\title{
HIGH-TECH BUILDINGS MARKET TRANSFORMATION PROJECT
}

\author{
Cleanroom Energy Benchmarking \\ High-Performance Fume Hood Demonstration/Test \\ Market Transformation Activities
}

FINAL REPORT TO

California Institute For Energy Efficiency

Pacific Gas and Electric Company

\author{
Tengfang Xu, Bill Tschudi, Geoffrey Bell, Evan Mills, and Dale Sartor, \\ Applications Team \\ Building Technologies Department \\ Environmental Energy Technologies Division \\ Ernest Orlando Lawrence Berkeley National Laboratory \\ University of California \\ 1 Cyclotron Road \\ Berkeley, California 94720
}

November 2001

\footnotetext{
This project is funded by California utility customers and is administered by Pacific Gas and Electric Company under the auspices of the California Public Utilities Commission. Copyright (C) 2001 Pacific Gas and Electric Company. All rights reserved. The research reported here was funded, in part, by the California Institute for Energy Efficiency (CIEE), a research unit of the University of California. Publication of research results does not imply CIEE endorsement of or agreement with these findings, nor that of any CIEE sponsor. This work was also supported by the Assistant Secretary for Energy Efficiency and Renewable Energy, Office of Building Technology, State and Community Programs, Office of Building Research and Standards of the U.S. Department of Energy under Contract No. DE-AC03-76SF00098.
} 


\section{PG\&E Disclaimer}

Reproduction or distribution of the whole, or any part of the contents of this document without written permission of PG\&E is prohibited. The document was prepared by PG\&E for the exclusive use of its employees and its contractors. Neither PG\&E nor any of its employees makes any warranty, express or implied, or assumes any legal liability or responsibility for the accuracy, completeness, or usefulness of any data, information, method, product or process disclosed in this document, or represents that its use will not infringe any privately-owned rights, including but not, limited to, patents, trademarks, or copyrights. 


\section{Table of Contents}

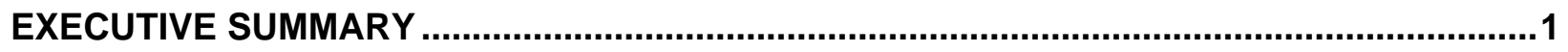

Cleanroom Energy Benchmarking............................................................................................................................................2

High-Performance Fume Hood Demonstration and Test .......................................................................................3

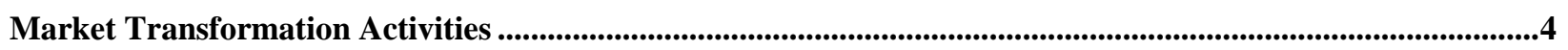

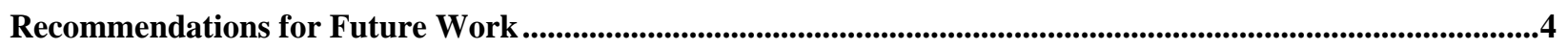

1. TASK ONE-CLEANROOM ENERGY BENCHMARKING....................................................5

1.1 Introduction ...........................................................................................................................................................................5

1.2 Goals and Approach ...........................................................................................................................................6

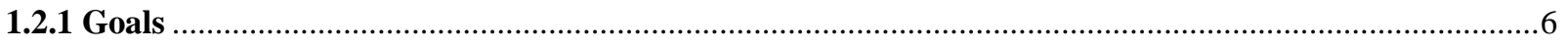

1.2.2 Approach

1.3 Results and Discussion ..................................................................................................................................................

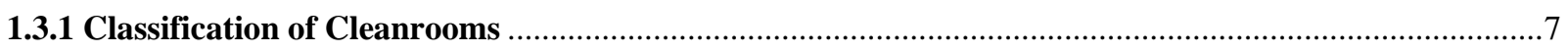

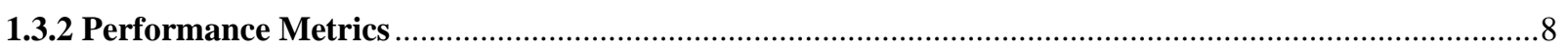

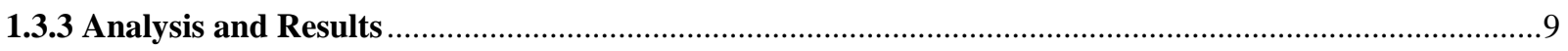

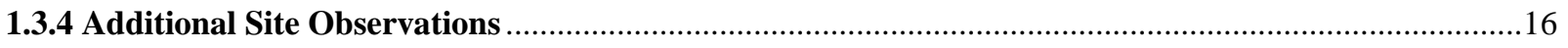

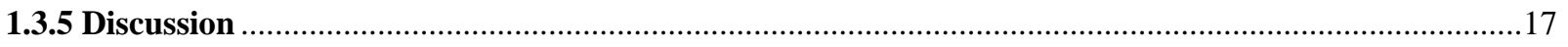

1.4 Conclusions .................................................................................................................................................19

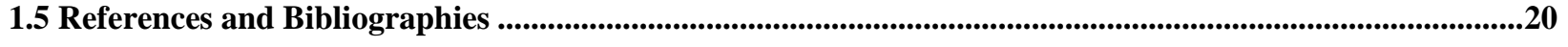

2. TASK TWO-HIGH-PERFORMANCE FUME HOOD DEMONSTRATION AND TEST...........21

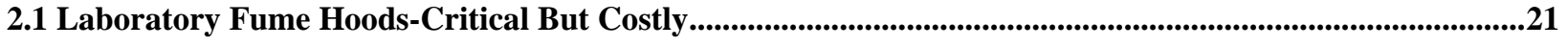

2.2 Containment Innovation ............................................................................................................................................................21

2.3 Field Trials Validate Performance ................................................................................................................................22

2.4 Post-Occupancy Evaluation ................................................................................................................................................22

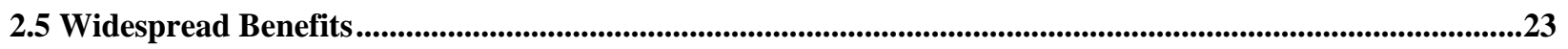

2.6 Project Supporters...............................................................................................................................................24

3. TASK THREE-HIGH-TECH BUILDINGS MARKET TRANSFORMATION SUPPORT

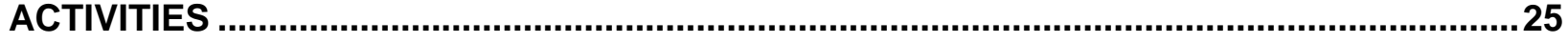

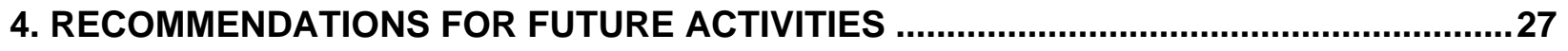

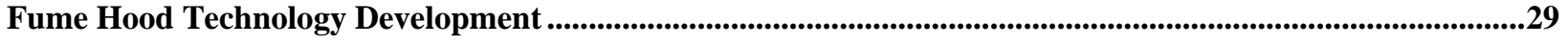

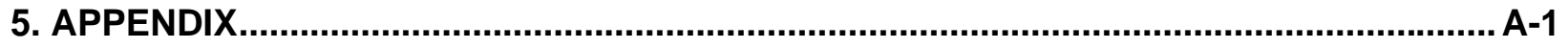




\title{
HIGH-TECH BUILDINGS MARKET TRANSFORMATION PROJECT
}

\author{
Cleanroom Energy Benchmarking \\ High-Performance Fume Hood Demonstration/Test \\ Market Transformation Activities
}

\author{
FINAL REPORT TO \\ California Institute For Energy Efficiency \\ Pacific Gas and Electric Company
}

\author{
Tengfang Xu, Bill Tschudi, Geoffrey Bell, Evan Mills, and Dale Sartor, \\ Applications Team, Building Technologies Department, \\ Environmental Energy Technologies Division \\ Lawrence Berkeley National Laboratory
}

\section{Executive Summary}

High Tech industries that rely on buildings containing cleanrooms and laboratories are very important to California's economy and have a large and growing influence upon Pacific Gas \& Electric Company's service territory. PG\&E, realizing the importance of these industries and the large potential for energy efficiency savings, contracted with Lawrence Berkeley National Laboratory (LBNL) and Rumsey Engineers through the California Institute for Energy Efficiency (CIEE) to perform market transformation activities specifically targeted for energy intensive industrial buildings containing cleanrooms and laboratories. These activities have broad applicability to many of California's industries and institutions. The industries utilizing these types of facilities include electronics (semiconductor, disc drive, flat panel display, and their suppliers), biotechnology, pharmaceutical, automotive, aerospace, health care, and foods.

This final report summarizes the activities and outcomes from the three tasks of the project: Task 1) Cleanroom Energy Benchmarking, Task 2) High-Performance Fume Hood Demonstration/Test, and Task 3) General project and Market Transformation Activities.

The first task was to benchmark environmental systems' energy use in facilities with cleanrooms. While this project was originally intended to focus on the electronics (high-tech) and biotechnology (biotech) industries, the benchmarking techniques and the metrics used are equally applicable to any cleanroom. Ultimately, due to some customers' inability to reach agreement with the PG\&E monitoring agreement, only electronics companies participated.

The second task was the demonstration and testing of a High-Performance Laboratory Fume Hood developed by LBNL. This demonstration and testing was performed at the University of California-San Francisco in an operating laboratory.

The third task included miscellaneous market transformation and outreach activities with the objective of influencing energy efficiency in the high-tech buildings market, identifying customer needs, and identifying barriers. This included participation in various forums that influence energy related aspects of high-tech buildings such as the Silicon Valley Manufacturer's Group, ASHRAE's cleanroom and laboratory technical committees, ACEEE, Cleanrooms East/West, Sematech, EPA and DOE's Labs for the $21^{\text {st }}$ Century, etc. Throughout the course of this project, considerable industry and institution interest and support for these activities was evident. 


\section{Cleanroom Energy Benchmarking}

Cleanroom benchmarking is particularly important to PG\&E's high tech customers because there is little industry data available to enable them to compare energy use. The lack of standard comparison metrics makes it difficult or impossible to set appropriate design goals, compare performance over time, and compare performance against other similar cleanrooms. Facility managers and designers know these buildings are energy intensive but lack the metrics and the data to quantify cleanroom energy performance. The goals of this project were to identify the metrics of importance for energy comparisons, and to collect operating benchmark data through physical measurements for a sampling of various classifications of cleanroom facilities. This data was placed into a database so that building owners, operators, and designers could understand how their facility's energy performance compares to others. A database format was developed to enable the data to be organized and to facilitate reporting and comparisons. Metrics to facilitate comparisons were developed (see the details of "General Cleanroom Benchmarking Plan" in the Appendix Section). Data for fourteen cleanrooms was obtained and entered into the database. Then site-specific reports for the measured facilities were prepared and furnished to PG\&E and the participating customers. Anonymous versions of these reports are included in the appendices. Energy end use such as is shown in Figure 1, as well as detailed system metrics were provided.

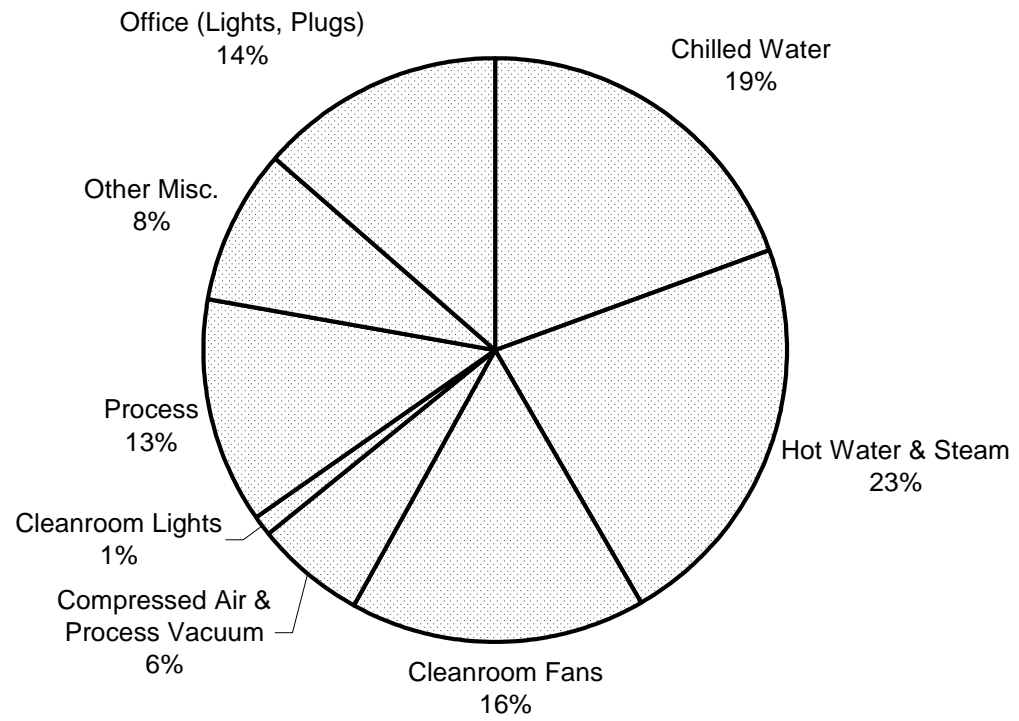

Figure 1. Production cleanroom energy breakdown.

To be able to compare performance in a meaningful way and begin to identify best practices, additional data for many more cleanrooms will be required. Since cleanrooms, and the energy intensity associated with the HVAC systems, vary (in part) depending upon their cleanliness classification; each cleanliness class should be benchmarked by a statistically significant number of data sets.

For the fourteen cleanrooms and cleanliness classes (three) that were benchmarked, energy end use was determined. Energy efficiency opportunities were noted and identified to the cleanroom operators. These recommendations were based on observations while on-site, and through review of the data. They were not intended to be a comprehensive study of all that could be done, however, in every facility the team identified a number of short and long term opportunities to improve efficiency. Further follow-up by PG\&E is recommended to encourage the customers to implement as many of the recommendations as practical.

Detailed site reports (14 cleanrooms in 7 facilities) were prepared and provided to PG\&E and the participating PG\&E customers. Anonymous versions of the site reports were prepared and will be reported through the LBNL website. This report summarizes the analysis of the metrics from the individual site reports. Graphical summaries of information for each of the major metrics are included to allow easy comparisons. The observations for energy efficiency opportunities are also summarized. 
Benchmarking reveals the following:

1. Energy performance of recirculation air systems and make-up air systems varied widely, including in cleanrooms of the same cleanliness class. Similarly, air change rates and cleanroom air velocities varied widely, exceeding industry (Institute of Environmental Sciences and Technology (IEST)) recommended limits. The range of recommended air change rates appears to be too stringent. There is a need to develop a scientific basis for the recommended ranges.

2. Immediate opportunities exist for energy savings by reducing recirculation airflow rates in most cleanrooms. While traditional ranges of "acceptable" air changes may be shown to be arbitrarily set too high, it is still possible to reduce airflow and remain in compliance with air change rates recommended by industry guidelines. Dramatic reductions in fan power (and related fan heat) are possible in most of the cleanrooms in the study.

3. In general, air systems with lower air system pressure drops (low resistance to airflow) are more efficient $(\mathrm{cfm} / \mathrm{kW})$ than those with high pressure drops. Wide variations in air resistance were primarily due to choices made during design.

4. Additional efficiency can be obtained by optimizing system and component design and can lead to significant improvements. Changes in design philosophy for new designs, and retrofitting more efficient systems and components represent opportunities.

5. Facility managers, engineers, and cleanroom designers currently do not have the information to know whether their systems are high or low in efficiency performance. Most do not understand the performance of their own systems and all have little information to allow comparison to others.

6. There are a myriad of issues in determining which type of air management system is right for a given application. Owners and designers have traditionally not considered life cycle cost decisions as important as other technical considerations.

7. Process loads were consistently found to be significantly lower than design values. This highlights the need to focus on accurately developing the process design load, and to size HVAC systems for flexibility in growth while operating efficiently at part load. Most of the facilities central plant systems had significant energy efficiency opportunities. These include more traditional issues such as chiller efficiency, pumping configurations, control issues, use of "free cooling," etc. While the metrics obtained through benchmarking provide valuable information for performance comparison, further data is needed to bracket the range of current operation. Because the sample size from this study is not statistically significant, statistical generalization cannot be made. Some indication of the range of variability was obtained, however, it is not possible to single out "best" practices with such a limited sample size.

\section{High-Performance Fume Hood Demonstration and Test}

The High-Performance Laboratory Fume Hood (The "Berkeley Hood") under development by LBNL was demonstrated at UC San Francisco. This device uses a patented air containment design that reduces exhaust of conditioned air by up to 70\%. As part of this project, the hood was first installed for demonstration at the PG\&E Pacific Energy Center during the Labs for the $21^{\text {st }}$ Century Conference in San Francisco. Demonstration for the conference attendees was very successful and raised considerable interest in the technology.

LBNL arranged for demonstration and testing of the Berkeley Hood in an operating laboratory at UCSF. LBNL completed prototype development prior to installation of the hood and refinement of the design continued throughout the project. LBNL arranged for key industry partners such as Labconco and Seimens, to donate equipment and services for the demonstration. LBNL coordinated the installation and initial operation of the hood at UC San Francisco in an operating laboratory environment. A series of tests, including an ASHRAE 110 test (the industry standard test method for fume hoods) and other performance tests were successfully performed to demonstrate containment and operational characteristics for this hood. Notably, the pre-existing standard hood failed the tests which is consistent with reports that standard hoods often do not achieve intended performance levels. 
Data were also obtained to estimate energy performance of the hood compared to a standard hood. Conservatively we estimate that each new Berkeley Hood will reduce peak electrical load about $2.3 \mathrm{~kW}$ and save $8.5 \mathrm{MWh} / \mathrm{year}$.

We estimate a stock of 85,000 to 170,000 fume hoods in California, which offer potential electricity savings of 360 to $720 \mathrm{GWh}$ and 0.1 to $0.2 \mathrm{GW}$ (assuming 50\% market penetration and 50\% savings per hood). Note that our savings estimates (based on electricity prices of $\$ 0.08 / \mathrm{kWh}$ and $\$ 120 / \mathrm{kW}$ demand charges) predate the energy crisis of 2001, at which time prevailing energy prices were three to four times higher in some areas than those used in this analysis.

The development and testing of the hood is described in detail in the High Performance Fume Hood overview report in the Appendix, and in a forthcoming special report for PG\&E with further details on the demonstration.

\section{Market Transformation Activities}

The third focus of the project involved market transformation activities targeted for high-tech buildings.

One area of activity involved outreach to building owners and operators through technical conferences and publications. A number of technical presentations and papers addressing various facets of the high-tech buildings work were prepared and presented. These activities are described later in this report in more detail and the presentation material and papers are included in the appendices.

In addition, the team prepared for and participated in several industry roundtable meetings and seminars hosted by PG\&E. Industry interest level was high at the roundtable meetings and conferences. In some sessions a lively exchange of industry views on needed technologies ensued. In these meetings, LBNL provided technical presentations discussing the High Tech buildings work and results of the project.

Another area of activity involved participation in technical committees addressing fume hood performance and safety issues.

\section{Recommendations for Future Work}

As a result of the project tasks and industry input, recommendations for future high-tech facilities energy efficiency activities were developed. These are described in the following sections. Some key recommendations include:

For cleanroom benchmarking:

1. Expand cleanroom energy benchmarking database with data from additional cleanrooms.

a. Additional data points for each cleanliness class are recommended to begin meaningful comparison based upon the variation observed to date. This data can be obtained through various means such as through additional site measurement, purchase of existing data, use of design data in combination with measured data, etc.

b. Benchmark cleanroom energy use in industries and applications other than electronics. Compare results across industries, and identify industry specific opportunities.

c. Develop case studies for best performing cleanrooms and identify best practices.

2. Develop a cleanroom self-benchmarking protocol for use by cleanroom owner/operators.

3. Develop a design-based cleanroom energy benchmarking protocol.

4. Implement key efficiency observations as identified in the cleanroom benchmarking work by trial use of the new cleanroom programming guide developed by LBNL with California public goods research funding.

5. Outreach through ASHRAE, ACEEE, Sematech, Silicon Valley Manufacturing Group, Northwest Energy Efficiency Alliance, SEMICON, Cleanrooms West, etc. Update and expand Cleanroom web site. Develop training materials and present selected cleanroom, laboratory, or data center topics at the Pacific Energy Center.

For cleanroom efficiency improvements:

1. Develop a standardized test procedure for fan-filter units commonly used in cleanrooms to provide a standardized comparison of energy performance. 
2. Investigate filter technologies and develop energy performance data for various filter types.

3. Assist PG\&E in developing a rebate or incentive program for cleanroom facilities. Obtain and compare manufacturers energy use information for various cleanroom related equipment such as:
a. HEPA filters
b. Fan-filter units
c. Cleanroom HVAC air handlers
d. Cleanroom exhaust fans
e. Provide incentive for reducing air velocity (air change rates) in cleanrooms based upon criteria to be developed by LBNL.

4. Make PG\&E customers aware of existing industrial efficiency information:
a. Motors
b. Pumps
c. Chillers
d. Compressors/compressed air systems

5. Develop programs to promote "free cooling" through case studies, workshops, or targeted rebate programs.

6. Investigate opportunity for widespread use of single (primary only), variable speed, chilled water pumping systems.

7. Investigate significance of leakage from cleanroom envelope. Develop a methodology to quantify cleanroom leakage and guidelines and/or technologies to find and fix leaks.

For the high performance fume hood:

Fume hood technology development

1. Develop improved safety testing and monitoring techniques

2. Create next-generation prototypes (esp. wider hood openings)

3. Identify and address failure modes

4. Perform additional Computational Fluid Dynamics (CFD) modeling

5. Analyze systems interactions.

Fume Hood Market Development

1. Improve estimates of energy savings potential

2. Form new industry partnerships

3. Address applications for other hood market segments (e.g. wet benches)

4. Outreach

5. Liaison with professional societies

6. Develop business case for commercialization

\section{Task One-Cleanroom Energy Benchmarking}

\subsection{Introduction}

Facility managers and designers know their buildings are energy intensive yet have few techniques to quantify cleanroom energy performance. Benchmarking identifies the energy end uses in a cleanroom. As expected, besides the process loads, which are often very intense, the mechanical systems are the most energy intensive in these buildings. Benchmarking the mechanical systems and components can provide useful information on system and component performance and provide a basis to identify energy-saving opportunities in cleanrooms.

HVAC systems in cleanrooms are dramatically different from their counterparts in commercial buildings in terms of reliability, safety requirements, and scale. The design of cleanroom HVAC systems is a specialty area requiring unique understanding of cleanliness guidelines, airflow quantities, room pressurization, code requirements, specialty equipment, tight control, and many more details. The HVAC systems must also operate reliably and safely. Since recirculation air systems use large amounts of fan power in moving large amounts of conditioned air through HEPA 
filters, the cleanroom, and return pathways they represent one of the largest energy end uses in a cleanroom. In addition, many processes requiring cleanrooms also have large make-up and exhaust airflow needs requiring huge amounts of energy to move and condition the displaced air. Energy intensity for mechanical systems in cleanrooms ranges between 4 to 100 times that of commercial buildings. There is, however, a lack of comparative data on the performance of cleanroom mechanical systems. To better understand existing cleanroom systems in high technology industries, and to better enable building owners, operators, and designers to compare energy use for a given cleanroom to others, it is necessary to benchmark energy performance in such facilities.

\subsection{Goals and Approach}

\subsubsection{Goals}

The cleanroom benchmarking task goals were to:

1. Develop energy metrics and protocol for obtaining benchmark data, and then obtain actual operating data to enable building operators to assess their cleanroom systems' energy performance;

2. Identify PG\&E customer specific opportunities for improvement; and

3. Identify generic issues and areas for improvement.

\subsubsection{Approach}

We developed a general benchmarking plan that was used throughout the project. The plan includes a discussion of the scope, procedure, metrics, database, and reporting. The intent of the plan was to provide an explanation of the project for PG\&E customers participating in the cleanroom benchmarking and it provided guidance for site-specific benchmarking plans. It identified and prioritized the systems to be benchmarked and it provided the metrics of interest to enable comparison of cleanroom environmental and process systems' performance. The general plan describes the database structure and measurement methods, including the device, equipment, time durations, and procedures for obtaining the data. A description of the plan is in the Appendix Section (Part 1) of this report.

Although the benchmarking for this project was initially directed at high technology and biotechnology customers, the metrics and procedures are intended to be equally applicable to cleanrooms in a wider range of industries and institutions. Ultimately, only "High Tech" (electronics) customers were included in the project due to difficulties with some Biotech customers reaching agreement with PG\&E for their monitoring agreement.

Site-specific measurement plans were developed and reviewed with all of the high-tech industry customers prior to proceeding with site data collection. Rumsey Engineers (formerly, Supersymmetry) had lead responsibility for preparation of the site-specific plans with input provided by LBNL and the other team members. Draft plans were first reviewed with the PG\&E customers to explain what would be done in their facility and to solicit customer input for modification to the measurement plan, if desired, to include any additional items of particular interest. Typically, the customers did not suggest changes to the basic plan, but the review was valuable in clarifying details about the facility and any existing data. Once the plan was finalized, site data consisting of existing energy billing or end use data, and measurements of energy and flows were obtained. To characterize the design of each cleanroom system, pertinent design information was obtained. Information was compiled from a review of building and system drawings, equipment data sheets, and interviews with building engineers. Physical layout was confirmed on-site to determine monitoring locations.

Measurements consisted of "spot" measurements where steady state operation was likely, to time series data taken over a period of approximately one to three weeks at each customer site. The data was then entered into the benchmarking database. Finally, site-specific reports were prepared to summarize and analyze the data collected; and to provide observations for efficiency improvements. The customer reports were then presented to the customer facility managers in a meeting at the customer's facility. Anonymous versions of the reports were also prepared for publication on the LBNL website. These reports provide a description of the facility systems, a summary of the findings, site observations, recommendations for further investigation, and the detailed measured data. 
During the course of the project, the project team including PG\&E customer representatives contacted a number of customers to solicit participants in the project. We found that there was a high level of interest in participating by most companies contacted even though many of the facility staff were extremely busy. Most companies expressed strong interest in the study to determine how their facility was performing and saw the data as extremely valuable. A series of meetings were held with many of the potential participants. Some of the PG\&E's customers that were interested, however, were not selected for monitoring due to irresolvable issues in the monitoring agreement.

Site measurements in the participating facilities began in June 2000 and were completed in August 2001. Rumsey Engineers, Inc. was selected to provide cleanroom technical assistance in preparation of the site measurement plan, and was responsible for all site measurement work. Measurement and test equipment was provided by PG\&E through the PG\&E Pacific Energy Center's tool lending library, and was supplemented with equipment provided by Rumsey Engineers. Rumsey Engineers also entered the benchmark data into a Microsoft Access database that was created specifically for the cleanroom benchmarking project.

A project website was established and maintained during the project to facilitate communications with the team members. This site was only accessible to the project team, however, the anonymous site reports, benchmark data and summary results will be published on the LBNL cleanrooms website.

\subsection{Results and Discussion}

Benchmarking cleanroom energy use in mechanical systems and components (HVAC primarily) provides valuable information concerning system and component level performance. Information on the performance of other less energy intensive systems is also valuable. This information can be used as a baseline for tracking energy performance over time, for energy comparison against other types of systems and components, for identifying operational and maintenance issues, and for setting design criteria for future cleanroom projects. Use of the benchmarking metrics provides an effective way to understand energy end use in complex cleanroom facilities. The energy benchmarks can help to prioritize measures to achieve improvements in system energy efficiency. Analysis of the data can provide better understanding of system performance, and can suggest good design practices for longlasting energy-saving opportunities in cleanrooms.

The following summarizes key parameters and findings from the study.

\subsubsection{Classification of Cleanrooms}

Cleanrooms are classified according to how clean they are maintained. The Institute for Environmental Sciences and Technology (IEST), through ISO Standards that they develop, currently defines cleanroom cleanliness "classes". Previously, the standard was established through Federal Standard 209E and currently the industry is converting to follow ISO standards. As a result, there are some terminology changes occurring in the industry. These standards both set forth the allowable number of particles of a certain size for various class cleanrooms and provide recommended air change rates. This project focused (in part) on energy efficiency of air movement and did not involve assessments of cleanroom cleanliness.

The benchmarking project included the measurement and analysis of data from a total of fourteen operating cleanrooms. Table 1 includes a summary of the physical characteristics of the fourteen cleanrooms which were monitored, as well as relevant measurement and building information. Among these fourteen cleanrooms were five Class-10 (ISO Class-4) cleanrooms, seven Class-100 (ISO Class-5) cleanrooms, one Class-100/1000 (ISO Class-5/6) cleanroom, and one Class-10000 (ISO Class-7) cleanroom. Twelve cleanrooms were located in PG\&E territory in Silicon Valley, California and all were monitored in 2000 or 2001. Comparable data from two other cleanrooms located outside of California were available through prior work by Rumsey Engineers and are included in the analysis. 
Table 1. Physical Characteristics of Cleanrooms Tested

\begin{tabular}{|c|c|c|c|c|c|c|c|c|}
\hline ID & $\begin{array}{l}\text { ISO } \\
\text { Class } \\
\end{array}$ & Class & Location & $\begin{array}{l}\text { Year } \\
\text { Built } \\
\end{array}$ & $\begin{array}{c}\text { Cleanroom } \\
\text { Area }\left(\mathbf{f t}^{2}\right)\end{array}$ & $\begin{array}{c}\text { Ceiling } \\
\text { Height (ft) }\end{array}$ & $\begin{array}{c}\text { Monitoring } \\
\text { Start } \\
\text { Date } \\
\end{array}$ & $\begin{array}{c}\text { Monitoring } \\
\text { End } \\
\text { Date } \\
\end{array}$ \\
\hline 3 & 4 & 10 & Fremont, CA & 1998 & 21300 & 10 & $6 / 15 / 00$ & $6 / 29 / 00$ \\
\hline 10 & 5 & 100 & Fremont, CA & 1998 & 10400 & 12 & $6 / 15 / 00$ & $6 / 29 / 00$ \\
\hline 11 & 5 & 100 & Milpitas, CA & 1996 & 21400 & 9.5 & $10 / 10 / 00$ & $10 / 19 / 00$ \\
\hline 12 & 5 & 100 & Milpitas, CA & 1996 & 2850 & 9 & $10 / 10 / 00$ & $10 / 18 / 00$ \\
\hline 13 & 5 & 100 & San Jose, CA & 1990 & 4300 & 9 & $10 / 23 / 00$ & $11 / 10 / 00$ \\
\hline 14 & 5 & 100 & San Jose, CA & 1990 & 7950 & 9 & $10 / 24 / 00$ & $11 / 10 / 00$ \\
\hline 15 & 5 & 100 & Nampa, ID & 1993 & 11300 & $10^{*}$ & $11 / 29 / 99$ & $12 / 3 / 99$ \\
\hline 16 & 4 & 10 & Albuquerque, NM & 1988 & 12500 & 9 & $10 / 13 / 98$ & $10 / 19 / 98$ \\
\hline 17 & $4 / 5$ & $100 / 1000$ & San Jose, CA & N/A & 3950 & 10 & $4 / 23 / 01$ & $4 / 30 / 01$ \\
\hline 18 & 5 & 100 & San Jose, CA & N/A & 10570 & 10 & 4/30/01 & $5 / 7 / 01$ \\
\hline 19 & 7 & 10,000 & San Jose, CA & 1996 & 5025 & 12 & $6 / 13 / 01$ & $6 / 16 / 01$ \\
\hline 20 & 4 & 10 & San Jose, CA & 1996 & 725 & 12 & 6/13/01 & 6/16/01 \\
\hline 21 & 4 & 10 & San Jose, CA & 1996 & 710 & 12 & $6 / 13 / 01$ & 6/16/01 \\
\hline 22 & 4 & 10 & San Jose, CA & 1996 & 2180 & 9 & 6/13/01 & 6/16/01 \\
\hline
\end{tabular}

* Assumption-not verified

\subsubsection{Performance Metrics}

The general plan defines the metrics that were used during the course of the project (See Appendix for the full plan).

The metrics in Table 2 and the measured results are described below in more detail. The results are depicted graphically for easy comparison. 
Table 2. Selected Performance Metrics of Cleanroom Energy Benchmarking

\begin{tabular}{|l|l|l|}
\hline \multicolumn{1}{|c|}{ Metrics } & \multicolumn{1}{|c|}{ Definition } & \multicolumn{1}{|c|}{ Unit } \\
\hline $\begin{array}{l}\text { Recirculation Air Handler } \\
\text { Unit Efficiency }\end{array}$ & $\begin{array}{l}\text { Recirculation airflow rate per kW of } \\
\text { electricity used by recirculation air fans }\end{array}$ & $\mathrm{cfm} / \mathrm{kw}$ \\
\hline $\begin{array}{l}\text { Recirculation Air Change } \\
\text { Rate }\end{array}$ & $\begin{array}{l}\text { Recirculation airflow rate divided by the } \\
\text { volume of primary cleanroom }\end{array}$ & $\mathrm{ach} / \mathrm{hr}$ \\
\hline Cleanroom Air Velocity & $\begin{array}{l}\text { Recirculation airflow rate divided by the floor } \\
\text { area of primary cleanroom }\end{array}$ & $\mathrm{fpm}$ \\
\hline HEPA Filter Air Velocity & $\begin{array}{l}\text { Recirculation airflow rate divided by the } \\
\text { effective filter area of cleanroom }\end{array}$ & $\mathrm{fpm}$ \\
\hline $\begin{array}{l}\text { Make-up Air Handler Unit } \\
\text { Efficiency }\end{array}$ & $\begin{array}{l}\text { Make-up airflow rate per kW of electricity } \\
\text { used by make-up air fans }\end{array}$ & $\mathrm{cfm} / \mathrm{kw}$ \\
\hline Process Load Intensity & $\begin{array}{l}\text { Process load per unit of primary cleanroom } \\
\text { floor area }\end{array}$ & $\mathrm{w} / \mathrm{ft}{ }^{2}$ \\
\hline Chiller Efficiency & $\begin{array}{l}\text { Power demand of chiller per unit of cooling } \\
\text { generated }\end{array}$ & $\mathrm{kw} / \mathrm{ton}$ \\
\hline Pump System Efficiency & $\begin{array}{l}\text { Power demand per unit of cooling for water } \\
\text { system pumping }\end{array}$ & $\mathrm{kw} / \mathrm{ton}$ \\
\hline
\end{tabular}

\subsubsection{Analysis and Results}

An analysis of the data suggests several targets of opportunity for efficiency improvements. As discussed below, there are a number of areas that clearly have significant potential for energy savings. In addition, there are other potential areas for which further investigation is warranted. A summary of some of the more important issues follows:

\subsubsection{Recirculation Air Systems}

Efficiency issues in recirculation air systems. The benchmark results show wide variation in the efficiency of moving air through cleanrooms. To achieve and maintain a high cleanliness level, cleanrooms rely on constantly moving large quantities of air (high air-change rates) through high efficiency filters (HEPA filters). Our benchmarking accounted for the total airflow through a cleanroom and the energy to move it $(\mathrm{cfm} / \mathrm{kW})$. Figure 2 shows the various efficiencies that were measured for these systems, where larger values represent better energy efficiency. Different system configurations and cleanliness classes were included in the study. Overall, the recirculation air handling systems efficiency varied dramatically from cleanroom to cleanroom.

Recirculation systems' design use different concepts for the fans and the return air path and consequently exhibit widely varying energy efficiency. One scheme involves use of an open "plenum". In this scheme, air from multiple recirculation air handlers is fed into a large open space and then flows through High Efficiency (HEPA) filters into the cleanroom. In other schemes, the air is provided to the HEPA filters through ductwork which tends to have higher resistance to airflow. To illustrate the efficiency differences observed in this project, for the five ISO Class-4 cleanrooms (Class 10) the efficiency of the recirculation systems ranged from 3,086 to $4,839 \mathrm{cfm} / \mathrm{kW}$. Systems using pressurized-plenums had efficiencies of over 3,000 cfm/kW. Pressurized-plenum systems were considerably more efficient than ducted distributed systems tested.

Similar wide variations in performance were noted for the other cleanliness classes included in the project. For the ISO Class-5/6 cleanrooms, the efficiency of the recirculation air systems ranged from 1,087 to $10,138 \mathrm{cfm} / \mathrm{kW}$. Among these, the overall efficiency of the pressurized-plenum systems ranged from 4,831 to $10,138 \mathrm{cfm} / \mathrm{kW}$. 


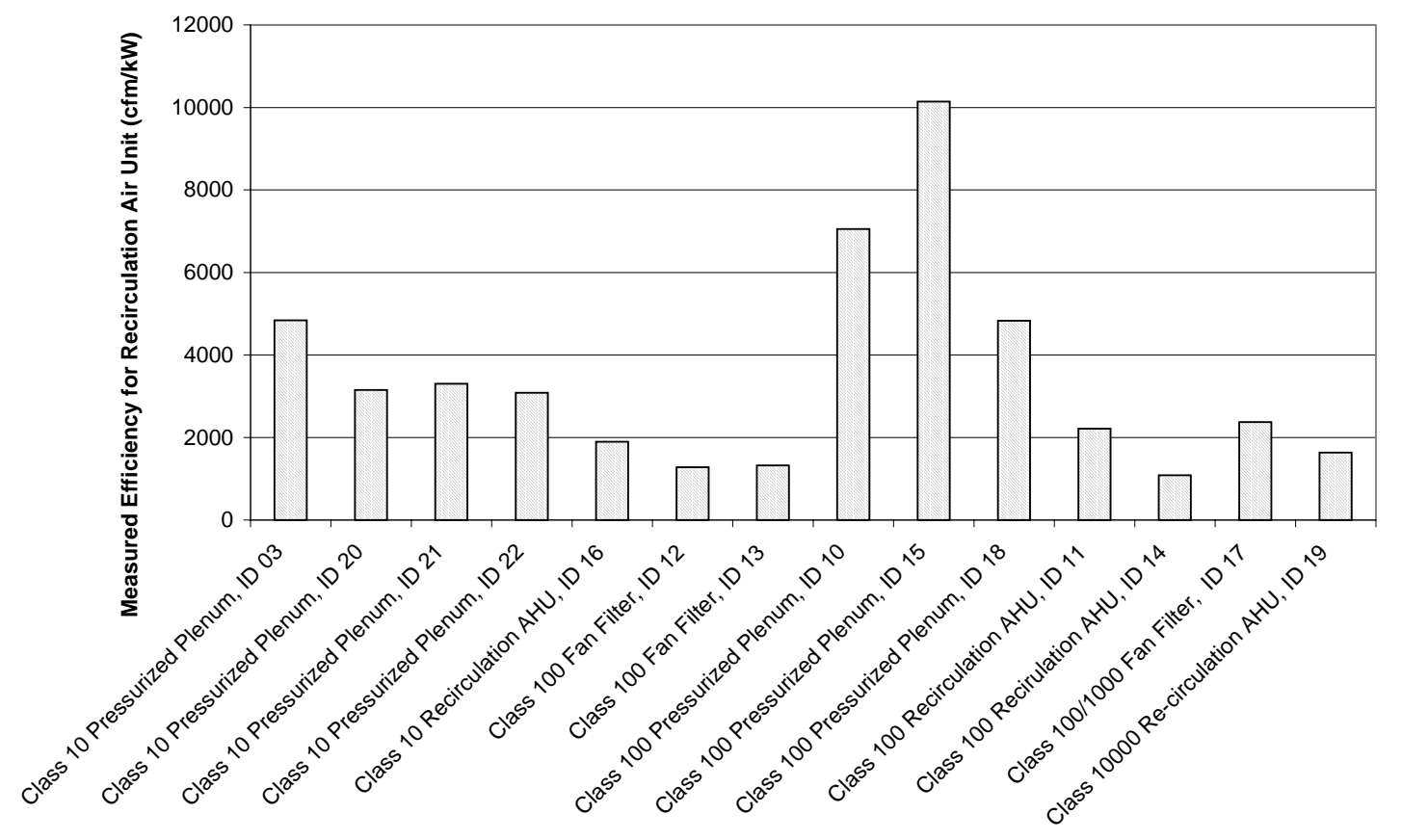

Figure 2. Recirculation system efficiency.

The pressurized-plenum systems were relatively more efficient compared to other types of distributed systems. Another recirculation system design utilizes multiple small fans to push air directly through HEPA filters. These fan-filter units are popular due to their ease of design, installation, and they are readily available. The measured efficiency of the fan-filter systems measured in this project was considerably less than that of the other types of systems. In general, pressure drops (resistance to flow) along the return path of the pressurized-plenum systems were lower while pressure drops for the distributed recirculation systems and fan-filter unit systems were higher. Overall, the fan-filter units and distributed recirculation air handlers in this study were rather inefficient in energy performance, ranging from 1,276 to 2,374 cfm/kW (for fan-filter units), and from 1,087 to 2,283 cfm/kW (distributed systems). This is thought to be due to a combination of inefficient motors in older fan-filter units, and inefficient design and layout of the recirculation pathways. In addition, in several cases, central recirculation units were necessary to condition the air in the recirculation path. For these systems the energy for both the fan-filter and the supplemental air handler were added together to evaluate overall recirculation system efficiency. In contrast, systems with pressurized plenums were much more efficient. Pressurized plenum systems were observed to be as high as $10,138 \mathrm{cfm} / \mathrm{kW}$ compared to distributed systems that were as low as $1,087 \mathrm{cfm} / \mathrm{kW}$.

Recirculation air change rate. There are a number of factors, which ultimately affect the cleanliness (i.e. the number of particles of a given size in the air where it could affect the process). For example, the amount of activity in the room, operating protocol, filter performance, equipment size and configuration, air pathways, thermal effects, and other factors all have direct or indirect impact on particle generation and movement. For the same cleanliness class of cleanroom, these factors will influence cleanliness. Cleanroom operation relies upon movement of large quantities of clean, filtered air to "sweep" particles away from areas of interest-such as where production is occurring. The amount of air changes required and the corresponding air velocity has developed over many years through rule of thumb methods.

The Institute of Environmental Science and Technology (IEST) recommends ranges of air change rates for each cleanliness class. Industry has traditionally followed the recommendations even though there is no documented scientific basis for the values. Some cleanrooms operate at different air change rates than those recommended by IEST either by design or by not being aware of the actual operating air velocity. Generally, deviation from IEST recommendations is towards higher air change values-with a feeling that more airflow is in some way "cleaner". Recent studies by Sematech and MIT have shown however that good results (i.e. production yields) can be achieved with much lower airflows. 
The results of this benchmarking project illustrate that there is a wide range of air change rates in the measured cleanrooms. It should be noted that the processes relying on clean conditions in these rooms achieved good results (yields) at all of the observed air change rates. Since the recirculation system accounts for a significant percentage of cleanroom energy use, and since fan energy varies approximately as the cube of the air velocity, lowering airflow is clearly a focus area for immediate efficiency improvement. In addition, decreasing fan power to recirculate cleanroom air would also reduce the overall cooling load due to the reduction in heat generated from the fan motors.

To illustrate this point, consider the recommended range of air change rates for Class-10 (ISO Class-4) cleanrooms with unidirectional airflow (IEST 1993). IEST recommends between 300 and 540 air changes per hour. This corresponds to cleanroom air velocities between 50 and $90 \mathrm{fpm}$ (or $0.254-0.457 \mathrm{~m} / \mathrm{s}$ ) based upon a ceiling height of 10 feet and full ceiling filter coverage.

Actual recirculation system air changes and corresponding velocities for all cleanrooms can be seen in Figure 3. This illustrates a wide variation in these parameters. For the five Class-10 (ISO Class-4) cleanrooms, measured air change rates were $385,474,516,591$, and $678 / \mathrm{hr}$ each, with corresponding average air velocities between $58 \mathrm{fpm}(0.3 \mathrm{~m} / \mathrm{s})$ and $118 \mathrm{fpm}(0.6 \mathrm{~m} / \mathrm{s})$. Obviously, some of these exceed IEST recommended values. For those cleanrooms with high air change rates, recommendations were made to consider reducing the airflow.

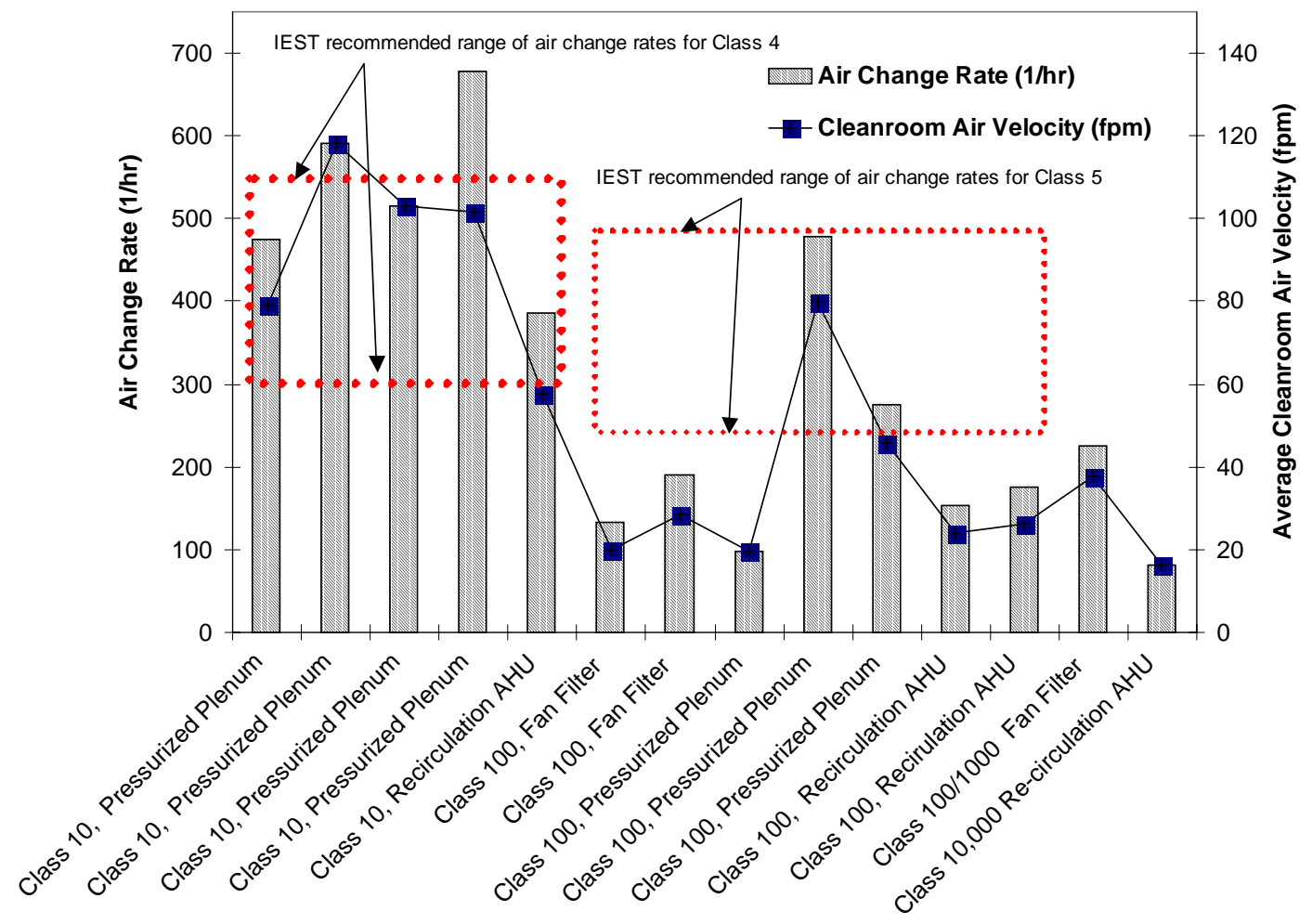

Figure 3. Air change rates and cleanroom air velocities.

Similarly, IEST also recommends a range for air change rates between 240 and 480/hr for Class-100 (ISO Class-5), which correspond to cleanroom air velocities between 40 and $80 \mathrm{fpm}$ (or 0.203-0.406 m/s) under all airflow patterns (unidirectional, non-directional and mixed). Again, a wide variation in airflow rates was observed. The measured air change rates were obtained in a range from 98 to $479 / \mathrm{hr}$, corresponding to average air velocities between $20 \mathrm{fpm}$ $(0.1 \mathrm{~m} / \mathrm{s})$ and $80 \mathrm{fpm}(0.4 \mathrm{~m} / \mathrm{s})$. Some of these were below the recommended lower limit of 240/hr. Although generalization of these findings based upon the limited number of cleanrooms tested may be premature, the range from 240 to 480/hr recommended by IEST for all Class-100 (ISO Class-5) appears to be higher than needed.

Some of the Class-10 cleanrooms had air change rates that exceeded the recommended maximum for a Class-10 cleanroom. On the other hand, we found the opposite in some of the Class-100 cleanrooms by having air change rates that were lower than the recommended range yet all cleanrooms were supporting production at acceptable 
levels. It appears possible to lower the airflow in some cleanrooms and still maintain class rating and adequate production. In theory, a 10\%-20\% reduction of airflow could achieve a $27 \%-50 \%$ energy savings. This indicates that there is great potential to save energy while maintaining effective contamination control.

Observations concerning recirculation systems. The bay and chase pressurized plenum recirculation air systems allow a large volume of air to travel at low velocity through an open chase-return space with minimal pressure drop.

In one cleanroom, the customer reported that the range of 80-100 fpm filter air velocity yielded reliable production results. When the air velocity was reduced below $80 \mathrm{fpm}$ (filter air velocity) during a trial period in 1999, production reportedly dipped, so the $90 \mathrm{fpm}$ filter air velocity target was restored. Although the production yield could not be definitively tied to lowering the velocity, it was decided to raise the velocity to its previous high level. This is indicative of the uncertainty concerning the cause of defects in the product. Without other supporting scientific basis, airflow is often increased in an attempt to solve a contamination problem.

Low velocity in air handlers, as well as low pressure drop throughout the recirculation path contribute to efficient systems. Use of pressurized plenums with raised floors and/or chase returns often provide such a low resistance pathway and contribute to good performance. On average, pressurized plenum recirculation systems for Class-100 (ISO Class-5) cleanrooms were most efficient when compared to the other types of recirculation systems serving the Class-100 (ISO Class-5) cleanrooms. One of the systems had a design $\mathrm{cfm} / \mathrm{kW}$ of 5,000, but it was operating at an impressive $10,138 \mathrm{cfm} / \mathrm{kW}$. This recirculation system was designed with large axial fans discharging air into an 8foot plenum. The air was returned under a four-foot high raised floor. The large airflow paths resulted in almost negligible pressure drop compared to other system designs. It was reported that the operator of the facility was unaware of the fact that this system was extremely energy efficient.

Improvements in the efficiency of air handling systems can be achieved through efficient layout, air balancing, reducing airflow in non-critical areas, using efficient fan motors, and using low pressure drop HEPA and pre-filters.

Recirculation system airflow setback during unoccupied periods should be considered. It is possible to reduce the recirculation airflow when the cleanroom served by these fans is unoccupied or otherwise has other low probability of generating particulates.

\subsubsection{Make-up Air Systems}

Outside air supply is needed to make up losses due to exhaust and to maintain pressurization within the cleanrooms. Exhaust rates are typically dictated by building and fire codes based upon the "occupancy" of the space. High exhaust rates are mandated when hazardous chemicals are present in certain quantities. Pressurization losses are primarily dependent upon the leak tightness of the clean envelope. All exhausted air and air lost in maintaining pressurization must be replaced by conditioned air from the make-up air system.

Energy efficiency of make-up air systems. Figure 4 shows the energy efficiency of make-up air systems for the cleanrooms in this project, where larger values represent better energy efficiency. The efficiency of the make-up air handler units ranged from approximately 540 to $1,800 \mathrm{cfm} / \mathrm{kW}$. Except for two cleanrooms (both were ISO Class5), the energy efficiency of make-up air systems was usually lower compared to those of the recirculation systems serving the same cleanrooms.

The efficiency of make-up air systems was observed to be lower than the recirculation systems. This is most likely due to the following:

1. Greater pressure losses (airflow resistance) along the make-up air pathways due to:
a. Longer, restrictive duct runs
b. Little space available for efficient duct layouts
c. Resistance of cooling/heating coils
d. Filter resistance
e. High face velocity in the air handler

2. Less-efficient fans and motors

3. Retrofitting air handlers into available space 


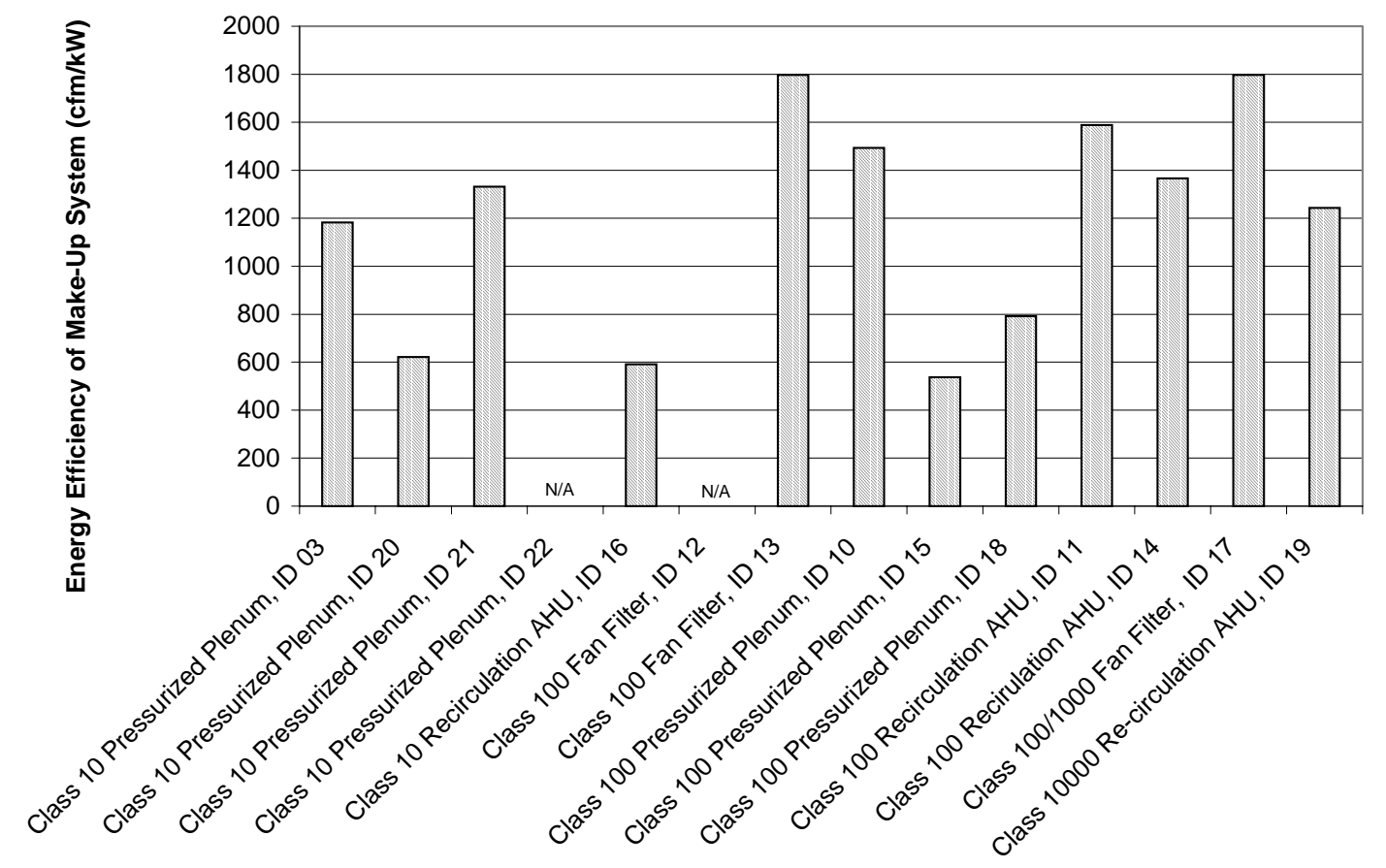

Figure 4. Energy efficiency for make-up air systems.

Unlike the recirculation systems, the make-up systems efficiency varied less dramatically from cleanroom to cleanroom but still varied by a factor of up to 3 . All of these indicate that the energy efficiency of make-up air systems should be able to be improved by integrating mechanical system considerations with architectural design at an early stage of the project, by adopting more efficient fans, and by more efficient duct sizing.

Observations concerning make-up air systems. In one case the measured temperature of the make-up air systems supply to the clean space varied significantly (up to $\pm 3^{\circ} \mathrm{F}$ ). This performance did not meet the original design criteria. It is likely that simultaneous cooling and heating of the air stream was occurring, due to poor control of cooling coil and heating coil valves. In these cases, investigation into the control system was recommended.

Other improvements can be made in certain make-up system's air reheat control. Better control of the amount of cooling and subsequent reheating can yield dramatic improvement. Lowering the amount of reheat to the make-up air may reduce energy consumption through lower boiler output. In one case, make-up air handlers operated with a fixed reheat set point. By reducing the amount of reheat, both the reheat load on the make up unit and the cooling load on the recirculation air handler are reduced.

\subsubsection{Chiller Efficiency}

Figure 5 illustrates the measured chiller efficiencies in ten of the facilities in this project where central plant data was obtained. The performance of chillers varied widely, ranging from $0.38 \mathrm{~kW} /$ ton to $0.84 \mathrm{~kW} / \mathrm{ton}$. The chiller data in Figure 5 represents the measured central plant chiller performance, where lower values indicate better energy efficiency. These chillers may serve multiple cleanrooms as well as other parts of the facility. Therefore, there is no direct correlation to each cleanroom and it is appropriate to examine the chilled water systems separately. 


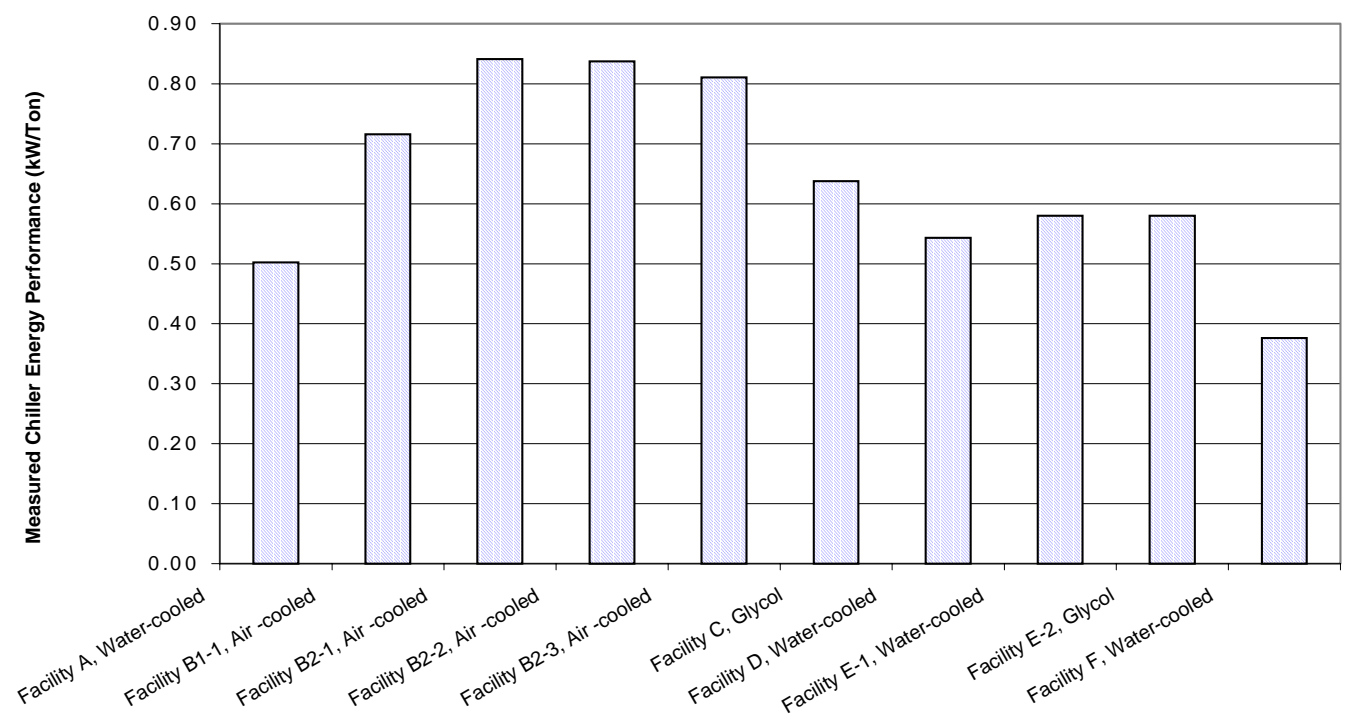

Figure 5. Chiller efficiency.

The results also show that an air-cooled chiller plant is likely to be less efficient than a combined water-cooled chiller and cooling tower system (evaporative cooled). Use of an evaporative cooled chiller system to replace existing air-cooled chiller system could reduce chilled water energy consumption by as much as $15 \%-30 \%$. Typical efficiencies for an efficient evaporative cooled system can be $0.6 \mathrm{~kW} /$ ton or almost half of that for some measured systems. Existing efficiency information on chiller performance is readily available and the benchmarking participants were encouraged to review this material. Two good sources of information are given on the following websites: (http://www.eren.doe.gov/femp/procurement/le_chiller.html) and (http://www.pge.com/cooltools)

Observations concerning chillers. The measured performance of a glycol-chilled water system was less efficient than a water-only chilled water system. For example, the efficiency of the measured glycol-chilled water system was very poor $(1.6 \mathrm{~kW} / \mathrm{ton})$ due to the use of central plant chilled water for the condenser side of the glycol chillers. For this case, an efficiency gain for the glycol-chilled water system could be made by installing a cooling tower to supplement the central plant chillers.

All of the $48^{\circ} \mathrm{F}$ chillers monitored showed very low differential temperatures $\left(2^{\circ} \mathrm{F}-5^{\circ} \mathrm{F}\right)$. This indicates that the chilled water flow is likely to be greater than needed to maintain cooling capacity. By allowing the temperature difference to increase, the efficiency of the chiller can be improved and less chilled water flow would be required, thus saving pumping energy.

In one case, site measurements highlighted that some chillers were frequently cycling on and off. The cycling not only wasted energy, it caused excessive wear on the equipment and could lead to premature failure. Improved control and operation, e.g., running fewer chillers at closer to their rated capacity can result in higher efficiency. Monitoring of chillers (and manufactures data) illustrates that the chiller efficiency often improves with loading, so multiple chillers should be staged, when possible, to achieve maximum efficiency for the system.

Other measures to increase chiller efficiency include 1) lowering chiller's condenser water supply temperature. The rule of thumb is that for a large centrifugal chiller a $1.2 \%-1.5 \%$ increase in efficiency is expected for each degree the condenser water temperature is lowered; 2) investigating to determine the lowest possible condenser water temperature; 3 ) resetting chilled water supply temperature-during nighttime and winter hours, less dehumidification of the air stream in the make up air handler is required. Based on the outside air conditions, the supply temperature of chilled water can be increased. Raising the temperature will reduce the energy input to the chillers by improving the chiller efficiency. 


\subsubsection{Chilled Water System Pumping Efficiency}

Observations of pumping issues. The efficiency of other chilled water system components (e.g., pumps, etc.) also varied significantly as did the overall energy performance of chilled water systems from facility to facility. The pumping systems in some chilled water systems experienced periodic power spikes, which were potentially damaging to the pumps. The systems apparently needed control tuning. In general, water-cooled chillers were more efficient, but pumping, system layout, sizing, and control also significantly impact the overall system energy use.

Site observations also indicated that oversized pumps resulted in inefficient operations. An example was that a tertiary loop included $200 \mathrm{HP}$ of installed pump motor equipment (excluding $100 \mathrm{HP}$ of a back-up pump) to serve an actual load of approximately $25 \mathrm{hp}$ for a recirculation air handler. This was likely the result of overly conservative estimates for cleanroom heat load as calculated by the designer. It is not uncommon for process equipment power demand to be overstated by manufacturers and then further increased through addition of safety factors by the designers.

\subsubsection{Process Load}

One of the major energy considerations for the design and operation of cleanroom HVAC systems is accurately determining the cooling load for removal of process heat. Process heat may be removed by use of process chilled water (water cooling), by exhaust systems (dedicated heat exhaust, general room exhaust, or process exhaust), or through the recirculation airflow. The amount of process load varies greatly from cleanroom to cleanroom depending upon the process and the density of process equipment. Initial sizing of the systems used to remove process heat loads often presents a design challenge. Too often, manufacturer's name-plate energy requirements are assumed, and then conservatisms are added for uncertainty and growth. Finally, inappropriate load diversification factors are applied. This leads to oversized HVAC systems that operate inefficiently.

Although the efficiency of process systems was not the main objective of the benchmarking work, the end use process load quantities were determined to obtain a complete picture of energy use. Figure 6 shows the measured process load intensity within the cleanrooms. Depending upon the process activities, the process load intensity ranged from 4 to $26 \mathrm{~W} / \mathrm{ft}^{2}$ among Class- 5 cleanrooms, and from 36 to $49 \mathrm{~W} / \mathrm{ft}^{2}$ among Class- 4 cleanrooms. These intensities of course were specific to the measured cleanrooms but can give the customers some indication for process loads should they expand or build new similar processes.

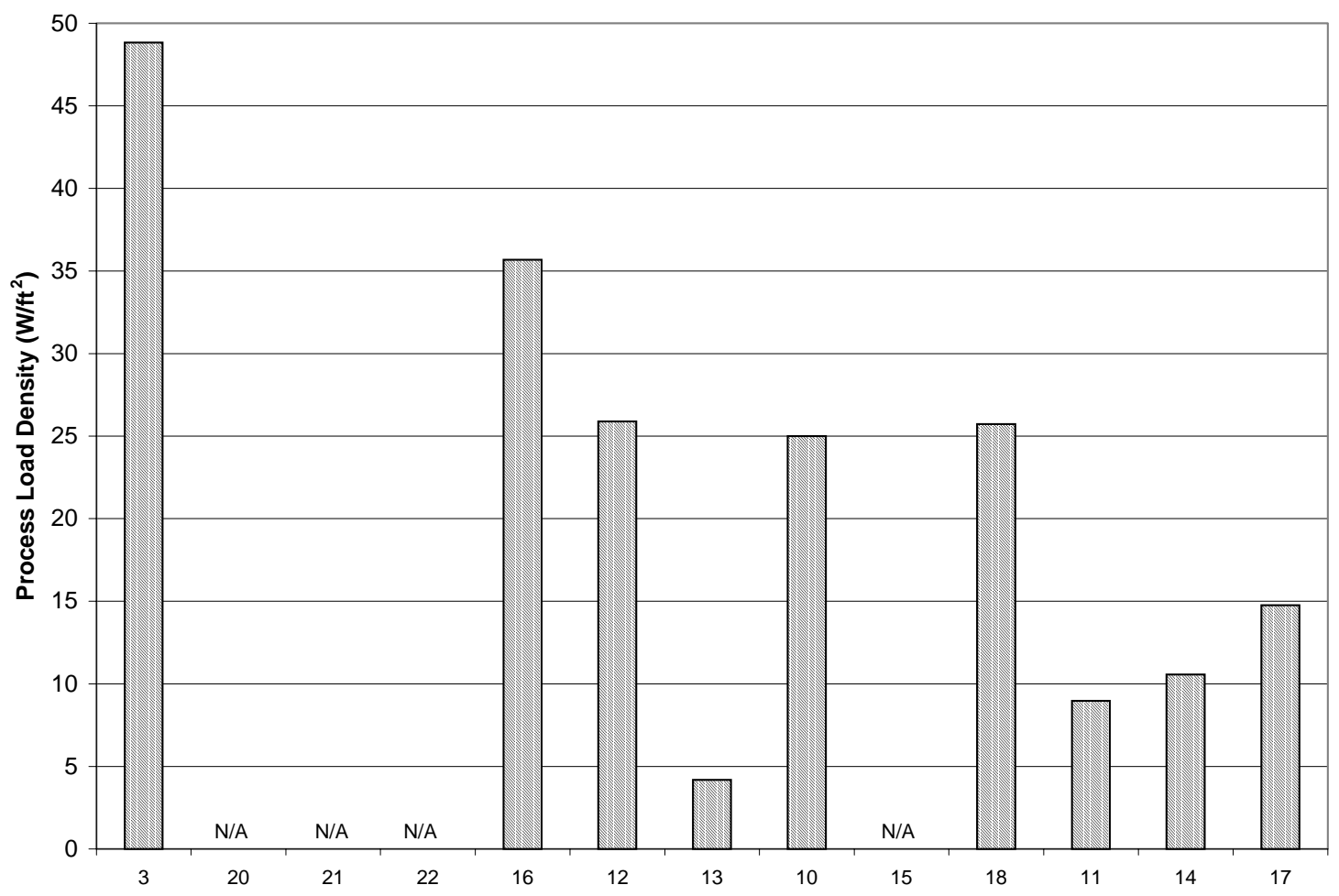

Figure 6. Cleanroom process load density (W/ft' ${ }^{2}$. 
While the magnitude of process loads is dependent upon the process occurring in the cleanroom, the measured result suggest a strong likelihood that process loads were over-estimated and that HVAC systems were commonly oversized. Although oversizing may be intentional for other reasons such as the provision for future expansion, tendencies to add extra conservatism in the design process result in extra energy waste. The design implication from this benchmarking analysis is that it is critical to have better estimates of process load for an energy efficient system design.

Observations concerning process energy. As expected, energy consumption for most cleanrooms did not vary significantly with the weather conditions or over time. Process loads and the related cooling loads were relatively constant. The process equipment heat load dominated energy consumption inside the cleanroom, but fan energy also contributed significantly to the heat load. Some of the process equipment has a high standby load, so even when the equipment is idle, the total process load did not drop significantly. The ability to reduce standby loads represents a significant opportunity.

\subsubsection{Additional Site Observations}

\subsubsection{Central Plant}

Utilities provided by a typical central plant include chilled water, steam or/and or hot water, and may include compressed air, nitrogen, de-ionized (DI) water, process vacuum, and house vacuum. Process systems often represent major loads with potential for efficiency improvements however the focus of this project was on the HVAC related systems. Data was obtained on other systems as time permitted. From the benchmarking, key energy savings opportunities for central plant systems were identified as follows:

1. Improve controls on the cooling towers. Some systems experienced dramatic on-off cycling, probably due to changes in ambient air wet-bulb temperature and load. The frequent cycling reduced its efficiency and could cause motor burnout. In addition, resultant condenser water supply temperatures to the chiller also swung up to $10^{\circ} \mathrm{F}$ within a short time (e.g., 10 minutes). This kept chillers from operating efficiently. The capacity controls combined with other measures such as multiple-speed fan motors, or damper modulating should be tuned to improve capacity control.

2. Improve efficiency in compressed air operation: There are several areas with potential for energy efficiency improvement that would require further investigation.

3. Take advantage of free cooling, consider measures for winter operation.

4. Utilize all existing tower capacity: A cooling tower can be used to provide cooling to the glycol chillers, and process chilled water replacing chilled water from the plant altogether at times. Overall, for a significant portion of the year when the cooling tower is operating, the load to the central chilled water plant will be reduced.

5. Arrange or configure a medium temperature chiller for tools and sensible cooling in the cleanroom.

\subsubsection{Clean Envelope System Leakage}

Leaks of conditioned air from the clean envelope (cleanroom, return air path, and make-up air path) can be responsible for large energy losses. A loss of conditioned air wastes the energy used to condition it as well as fan energy. For a continuously operational cleanroom this can represent a significant loss. A leaking air handler system was observed on one site placing additional demand on its make-up air system. Site observations led to recommendations to fill air traps in the condenser water drains of air handlers and to plug holes in air handlers that were used for other measurements. In general, inspecting the clean envelope for leakage could result in immediate low cost improvement due to reduction in make-up air conditioning and fan power reduction.

\subsubsection{Cleanroom Environmental Control}

Some cleanrooms that were monitored were on average $3^{\circ} \mathrm{F}$ to $5^{\circ} \mathrm{F}$ cooler than the stated specifications of $70^{\circ} \mathrm{F} \pm$ $2^{\circ} \mathrm{F}$. It may be possible to raise the temperature back to the design values, however this would need to be evaluated against personnel comfort issues. 
One site used electric humidifiers for humidity control in their cleanroom. Since electric humidifiers are the most energy intensive method of humidification, alternative humidifier types should be considered when the electric units require major repair or replacement. A steam-to-steam humidifier could be a good choice if clean steam is already plumbed to the building. An airless humidifier could also be considered.

\subsubsection{Discussion}

A wide variation of energy performance across different cleanrooms, different process loads, different system layouts, and different air systems was observed.

Based upon the limited number of cleanrooms tested in this study, a percentile ranking for each cleanroom's recirculation air system in terms of measured system efficiency was calculated and is presented in Figure 7. A rough trend line indicates that the medium energy efficiency of all the recirculation system was no more than 3,000 $\mathrm{cfm} / \mathrm{kW}$, which was rather poor compared to the best system performance. On the other hand, this indicates that huge energy saving opportunities likely exist for many of PG\&E's customers that are operating cleanrooms.

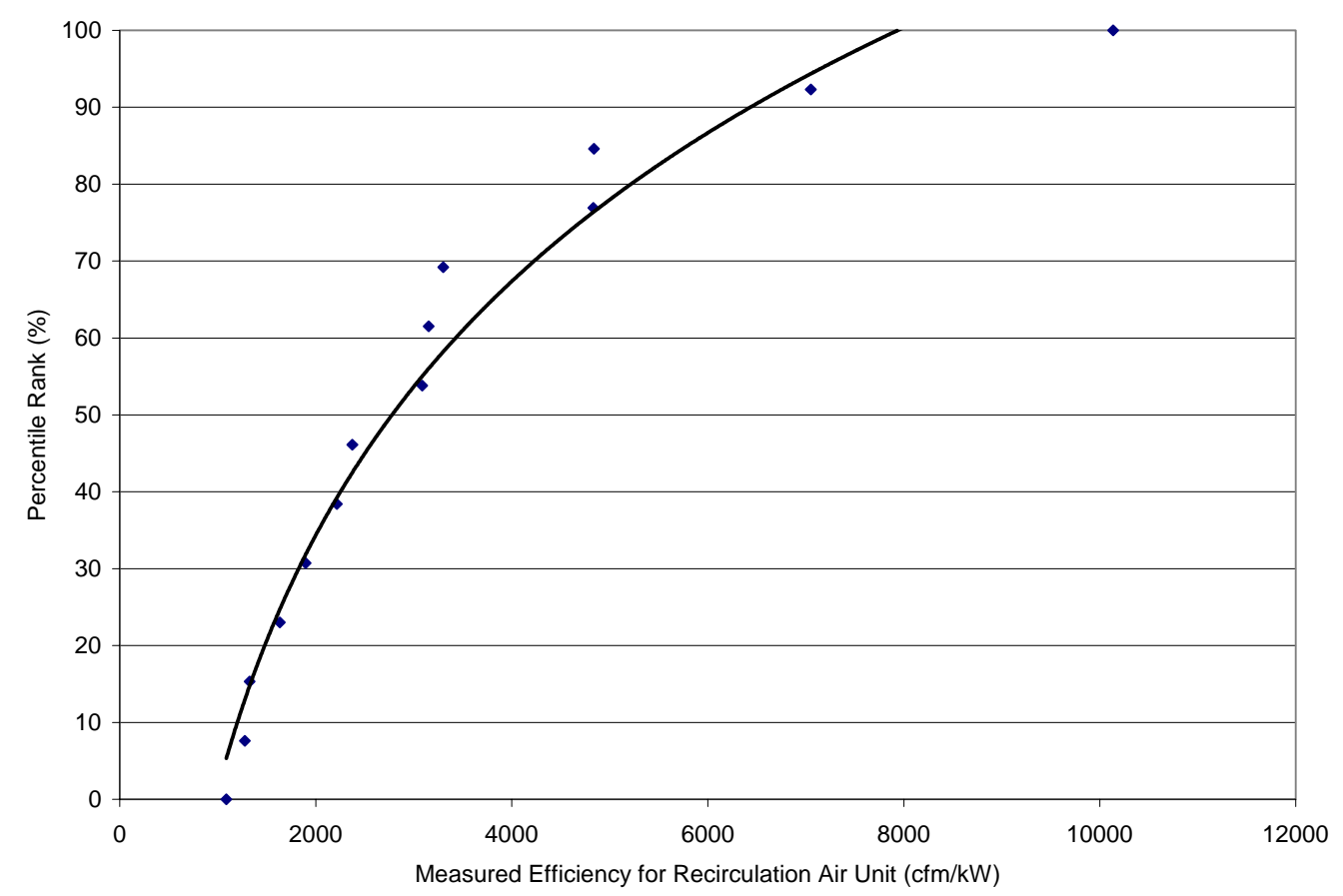

Figure 7. Comparison of energy efficiency of recirculation systems.

Further benchmarking activities are needed to enrich the database and to make statistically sound conclusions. In the meanwhile, the benchmarking results allow cleanroom owners/operators to compare the relative energy performance for the limited set of data, and this information should help them make informed decisions on potential energy efficiency improvements. Later, if the database is expanded it will provide information on the true range of possibilities and best practices will become evident.

Cleanroom air systems account for a large percentage of the energy budget. Depending on cleanliness requirements, cleanroom size, system design, and utility rates, the actual cost will vary significantly. To illustrate the order of magnitude cost, and the potential for cost saving, a rough order of magnitude estimate of the annual $\mathrm{kWh}$ cost for various cleanroom systems based upon the measured performance was determined. 
One way to obtain illustrative comparative estimates is to derive them using the actual measured efficiency for an assumed size of room (air volume) and electricity cost. This provides a good order of magnitude range to focus attention for further investigation. For an assumed class 100 cleanroom with recirculation air volume of 1,000,000 $\mathrm{cfm}$, operating 24 hours per day for a full year (8,760 hours), with electricity cost of $\$ 0.065$ per $\mathrm{kWh}$, and using the energy efficiency as measured for the class 100 recirculation systems (Figure 8), the example shows that annual $\mathrm{kWh}$ cost and can be as high as a half million dollars. This figure dramatically shows that an increase in recirculation system efficiency can result in a significant cost reduction in operating cleanrooms.

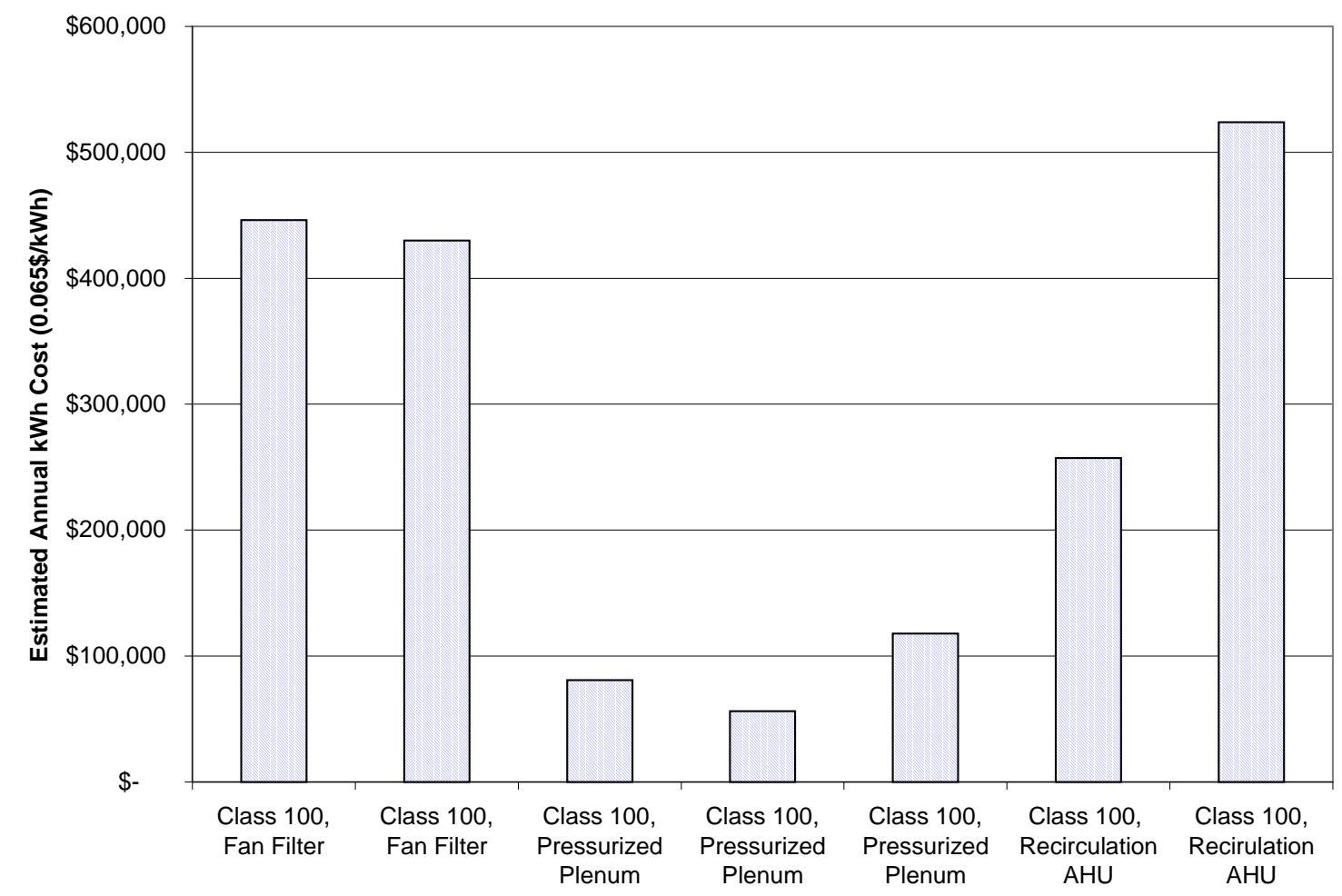

Figure 8. Estimated annual $\mathrm{kWh}$ cost for a 1,000,000 cfm class 100 recirculation system based upon actual measured efficiencies.

Other methods of obtaining the $\mathrm{kWh}$ cost estimates involve deriving it from the fan power intensity of recirculation air systems. When the recirculation system operating cost is determined, the results dramatically show that a slight decrease in recirculation fan power, (which could be realized through careful space planning, design, operation or control) would result in considerable cleanroom operating cost reduction.

To determine which air management system is the right selection for a cleanroom application involves many factors in addition to energy. Benchmarking highlights that owners and designers should carefully consider initial cost, operating cost, and process load in addition to other requirements such as contamination control and constructability. For example, the most efficient pressurized-plenum would require additional space. A large plenum would reduce air resistance however cost trade-off for additional building height could be the deciding factor. Another example is that fan-filter units are currently available that are more efficient than those measured in this project. They come with electronically commutated DC motors and can thereby significantly reduce the operating cost over their lifetime. This type of fan-filter unit requires larger air passageways and larger cooling coil surfaces in order to reduce air friction, however. This could increase the height requirements for the building and require more space for cooling coils. In addition, there is no easy way for designers and building owners to compare energy performance of fan-filter units. So the decision on the type and configuration of recirculation systems is dependent upon a number of issues. 
The appropriate volume of recirculation air is critical to efficient performance of cleanroom environmental systems and effective contamination control. There is a need to examine the scientific basis for recommended ranges of air change rates and corresponding average cleanroom air velocities currently published by IEST. An improved guideline based upon scientific understanding of small particle generation, movement, and deposition based upon improved modeling, or experimental measurements would be of great benefit to cleanroom designers and operators. Such a basis would lead to energy efficient performance while achieving highly productive and reliable cleanroom systems.

\subsection{Conclusions}

The following conclusions are made based upon an analysis of the benchmark data and individual site observations:

1. Energy efficiency for recirculation air systems and make-up air systems varied widely, even between cleanrooms of the same cleanliness classes. Similarly, air change rates and cleanroom air velocities varied widely, sometimes exceeding industry recommended ranges.

2. In general, air systems with lower pressure drops (less resistance to airflow) along the returned paths have higher efficiency $(\mathrm{cfm} / \mathrm{kW})$ than those with higher pressure drops. Wide variations in air resistance were primarily due to choices made during design. Fan-tower type recirculation air handler units with a pressurized plenum providing air to cleanroom ceiling filters usually result in better efficiency than using separate ductwork to each of the ceiling filters.

3. Recirculation systems using fan-filter units in general resulted in comparatively low efficiency. There is no standard energy performance data for these devices which makes selection difficult for designers and owners.

4. Immediate opportunities exist for energy savings by reducing recirculation airflow rates in most cleanrooms. Cleanroom air change rates are not well understood. The basis for air change rates is traditional and not determined scientifically. Air change rates recommended by IEST are, at best, guidelines based upon early cleanroom design rules of thumb. The range for air change rates recommended by IEST appears to be excessive in some applications and it was observed that even the maximum recommended values were exceeded. It appears that reductions in airflow rates in most cleanrooms would yield significant first cost saving and long term operating cost saving, but the industries that rely on clean environments need to have more scientific or experimental proof to assure that production would not be adversely affected. For the measured facilities, 20-50\% energy saving for recirculation air systems appeared easily attainable through low cost measures. Dramatic reductions in fan power (and related fan heat) are possible in most of the cleanrooms in the study.

5. The benchmarking analysis provided actual data on process loads. While these loads are specific to the processes occurring in this set of cleanrooms, the measured load intensity was considerably below design values specified by designers. This suggests that it is necessary and important for the designer to obtain more accurate estimates of process load, and to carefully apply conservatisms to avoid over sizing HVAC systems. Many HVAC systems were oversized for their current loads, resulting in inefficient performance.

6. Many opportunities for improving cleanroom systems' energy performance were noted. Opportunities exist in chilled water systems, and thermal environmental control. Measures can be taken to achieve better energy performance, such as performance monitoring, fine-tuning control and set-points, integrating free cooling, nighttime setback as to outdoor conditions and occupancies.

7. Because the sample size from this study is not statistically significant, statistical generalization cannot be made. Some indication of the range of variability is obtained, however, it is not possible to single out best practices with such a limited sample size.

8. Additional efficiency can be obtained by optimizing system and component design and can lead to significant improvement. Changes in design philosophy for new designs, and retrofitting more efficient systems and components represent opportunities. 
9. Facility managers, engineers, and cleanroom designers currently do not have the information to know whether their systems are high or low in efficiency performance. Most do not understand the performance of their own systems and all have little information to allow comparison to others.

10. Most of the facilities central plant systems had significant energy efficiency opportunities. These include more traditional issues such as chiller efficiency, pumping configurations, control issues, use of "free cooling," etc.

\subsection{References and Bibliographies}

ASHRAE . 1997. ASHRAE Handbook: Fundamentals, American Society of Heating, Refrigerating, and Air Conditioning Engineers, Inc., Atlanta.

ASHRAE . 1996. ASHRAE Handbook: HVAC Systems and Equipment, American Society of Heating, Refrigerating, and Air Conditioning Engineers, Inc., Atlanta, GA.

ASHRAE . 1995. ASHRAE Handbook: HVAC Applications, American Society of Heating, Refrigerating, and Air Conditioning Engineers, Inc., Atlanta, GA.

Energy Information Agency. 1997. Commercial Buildings Energy Consumption Surveys (CBECS). (http://www.eia.doe.gov/emeu/consumption)

Institute of Environmental Sciences and Technology (IEST). 1993. IEST Recommended Practice 012.1, IEST-RP-CC012.1, Considerations in Cleanroom Design. 940 East Northwest Highway, Mount Prospect, Illinois 60056-3422, USA.

Whyte, W. 1999. Cleanroom Design, $2^{\text {nd }}$ Edition. John Wiley \& Sons, Baffins Lane, Chichester, West Sussex, England. ISBN 0-471-94204-9.

Mills, Evan, G. Bell, D. Sartor, A. Chen, D. Avery, M. Siminovitch, S. Greenberg, G. Marton, A de Almeida, and L.E. Lock. 1996. Energy Efficiency in California Laboratory Type Facilities. Lawrence Berkeley National Laboratory Report, LBNL-39061. 


\section{Task Two-High-Performance Fume Hood Demonstration and Test}

\subsection{Laboratory Fume Hoods-Critical But Costly}

Fume hoods have long been used to protect workers from breathing harmful gases and particles by capturing hazardous airborne materials created in laboratories, manufacturing facilities, and other settings (Fig ES-1). These box-like structures offer users protection with a movable, window-like front "face" called a sash. Fans draw fumes out of the tops of the hoods. With approximately one million hoods in use in the U.S., aggregate energy use and savings potential is significant.

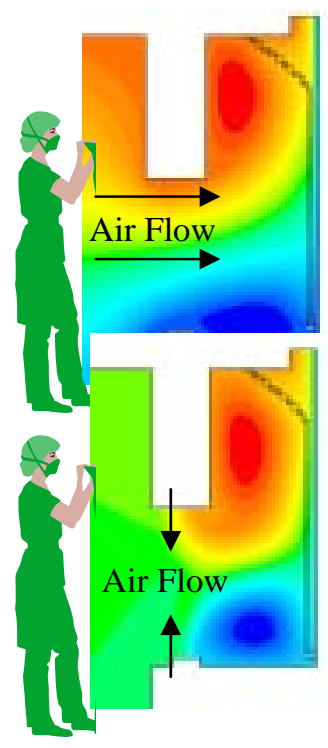

Figure ES-2. CFD

Modeling. Standard fume hood (above) and Berkeley Hood (below), with smaller vortices (red and blue circular areas) and the air curtain isolating interior and exterior air flows.
Conventional fume hoods rely solely on pulling air through the hood's open sash from the laboratory, around the worker, and through the hood workspace.

The generally accepted "face velocity" is around 100 feet per minute, depending on hazard level. Interestingly, recent research shows that increasing face velocity (and, consequently, air volume and energy use) does not tend to improve containment.

Instead, errant eddy currents and vortexes are induced in the hood and around hood users as air flows into the hood, reducing containment effectiveness and compromising worker safety (Figure ES-2).

Typical fume hoods exhaust large volumes of air at great expense. Furthermore, the energy to filter, move, cool or heat, and in some cases scrub (clean) this air is one of the largest loads in most facilities and tends to drive the sizing (first cost) and energy use of the central heating, ventilating and air-conditioning systems in the buildings in which the hoods are located. Fume hoods are a major factor in making a typical laboratory four- to five-times more energy intensive than a typical commercial building. A six-foot-wide hood exhausting 1200 cubic feet per minute, 24 hours per day, consumes more energy than an average house.

The most common energy-efficient modifications to traditional fume hoods are based on use of outside air (auxiliary air) or variable air volume (VAV) control techniques. While these approaches can save energy, they are complicated and costly to implement and operate, and do not address the worker safety issues inherent in the traditional fume hood design.

Innovation is hampered by various barriers stemming from existing fume hood testing/rating procedures, entrenched industry practices, and ambiguous and contradictory guidance on safe levels of airflow. These conditions make this technology area ripe for public interest research and development aimed at introducing innovative alternatives to current practice.

\subsection{Containment Innovation}

To address the shortcomings of existing approaches and to promote innovation in the marketplace, Lawrence Berkeley National Laboratory has developed and patented a promising new technology—The Berkeley Hood—that reduces the hood's airflow requirements by up to 70 percent while enhancing worker safety by supplying most of the exhaust air between the hood's operator and the work area. 


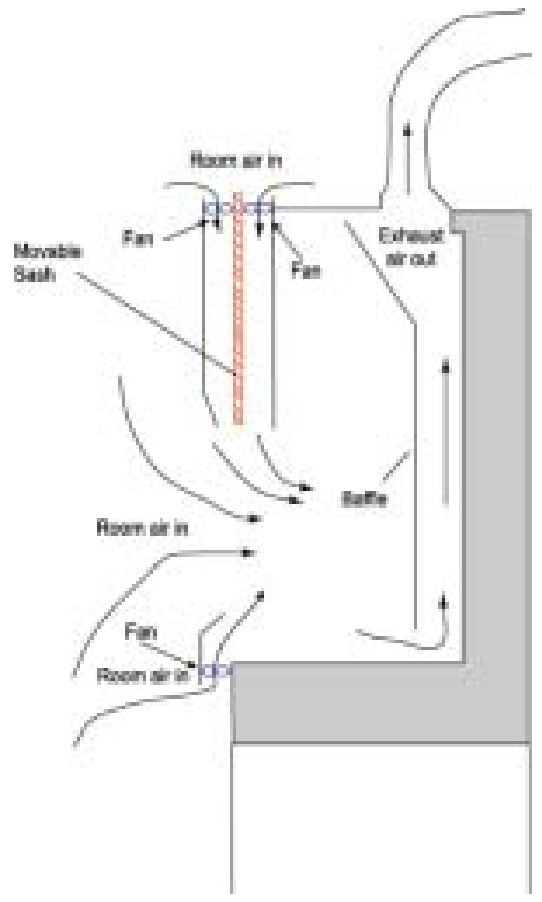

Figure ES-3 Schematic of the high-performance Berkeley Hood; sectional view shows airflow patterns.

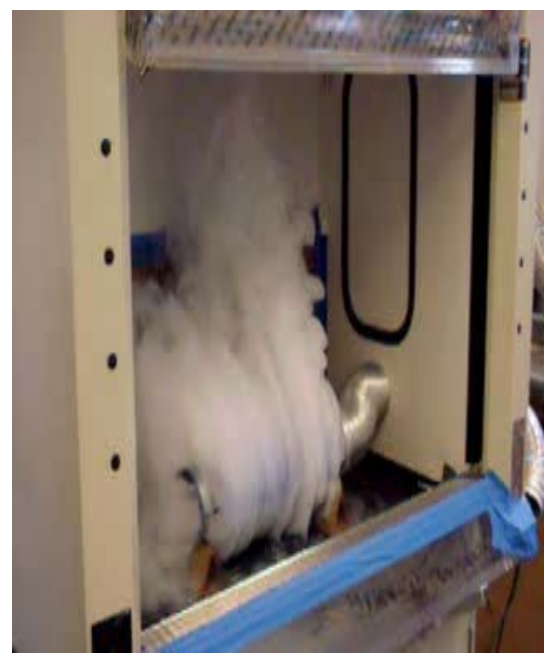

Figure ES-4. High-performance Berkeley Hood, showing full pollutant containment during flowvisualization test.
The LBNL containment technology uses a "push-pull" displacement airflow approach to contain fumes and move air through a hood (Figure ES-3). Displacement air "push" is introduced with supply vents near the top and bottom of a hood's sash opening. Displacement air "pull" is provided by simultaneously exhausting air from the back and top of the hood. These low-velocity airflows create an "air divider" between an operator and a hood's contents that separates and distributes airflow at the sash opening (unlike an air curtain approach that uses high-velocity airflow). When the face of a hood is protected by an airflow with low turbulent intensity, the need to exhaust large amounts of air from the hood is largely reduced. The air divider technology is simple, protects the operator, and delivers dramatic cost reductions in a facility's construction and operation.

The Berkeley Hood attains greater containment and exhaust efficiency, resulting in an effective and energy-efficient solution (Figure ES-4).

An added attraction of the Berkeley Hood is that it is expected to be less expensive than VAV fume hood systems. Savings from downsized heating, ventilating, and air conditioning systems will, in most cases, offset any first-cost premium of the Berkeley Hood.

The project team has developed several "alpha" prototypes of the Berkeley Hood for laboratory applications (Fig ES-5). LBNL is collaborating with various industrial partners to refine and apply the technology in research laboratories and microelectronics applications.

\subsection{Field Trials Validate Performance}

The University of California, at San Francisco (UCSF) field test has increased our understanding of operability of the Berkeley Hood under actual working conditions in a functioning laboratory.

At UC San Francisco, the Berkeley Hood has performed quite well in some cases exceeded expectations (Table ES-1), containing test smoke and tracer gas under all conditions down to 33 percent of full flow. Notably, the pre-existing standard hood failed certain tests for containment, even at full flow.

\subsection{Post-Occupancy Evaluation}

We conducted a post-occupancy evaluation of the UCSF demonstration, based on interviews with the hood user, a twenty-year veteran lab manager. The overall appraisal was excellent. Installation posed no undue inconvenience and had no adverse effects on the performance of hoodrelated tasks. The user saw no ways of making the hood more convenient or need for additional features. The adjustment from the old (standard) hood to the Berkeley Hood was "seamless" and did not require any special training. When asked if design changes were called for, none were identified. 
Table ES-1. ASHRAE 110 Test Results For Labconco Unit At UC San Francisco

\begin{tabular}{|c|c|c|c|c|c|c|}
\hline Test Type & Test Conditions & $\begin{array}{l}\text { Airflow } \\
\% \text { of } \\
\text { "normal" } \\
\text { (100 fpm) }\end{array}$ & $\begin{array}{c}\text { Berkeley } \\
\text { Hood } \\
\text { Containment } \\
\text { AM } \\
\text { (as mf'd) }\end{array}$ & $\begin{array}{c}\text { Berkeley Hood } \\
\text { Containment } \\
\text { Al } \\
\text { (as installed) }\end{array}$ & $\begin{array}{c}\text { Berkeley } \\
\text { Hood } \\
\text { Containment } \\
\text { AU } \\
\text { (as used) }\end{array}$ & $\begin{array}{c}\text { Standard } \\
\text { (Existing.) } \\
\text { Hood } \\
\text { Containment } \\
\text { @ } 100 \text { FPM }\end{array}$ \\
\hline Smoke & $\begin{array}{l}\text { Small volume } \\
\text { Smoke tube }\end{array}$ & $50 \%$ & Good & Good & Good & Fair \\
\hline Face Velocity ${ }^{a}$ & Sash Full Open & $50 \%$ & $\mathrm{~N} / \mathrm{A}$ & $\mathrm{N} / \mathrm{A}$ & $\mathrm{N} / \mathrm{A}$ & Fail \\
\hline Tracer gas $^{b}$ & $\begin{array}{l}\text { Sash Full Open; } \\
\text { three positions }\end{array}$ & $50 \%$ & Pass & Pass & Pass & Fail $^{c}$ \\
\hline Tracer gas $^{b}$ & $\begin{array}{l}\text { Sash movement; } \\
\text { three positions }\end{array}$ & $50 \%$ & Pass & Pass & Pass & $\mathrm{N} / \mathrm{A}$ \\
\hline Tracer gas $^{b}$ & $\begin{array}{l}\text { Safety margin } \\
\text { check }\end{array}$ & $50 \%$ & Pass & Pass & Pass & $\mathrm{N} / \mathrm{A}$ \\
\hline Tracer gas $^{b}$ & $\begin{array}{l}\text { Sash full open; } \\
\text { Three positions; } \\
\text { breathing zone } \\
\text { @ } 18 \text { inches }\end{array}$ & $50 \%$ & Pass & Pass & Pass & $\mathrm{N} / \mathrm{A}$ \\
\hline Tracer gas $^{b}$ & $\begin{array}{l}\text { Sash movement; } \\
\text { three positions; } \\
\text { breathing zone } \\
\text { @ } 18 \text { inches }\end{array}$ & $50 \%$ & Pass & Pass & $\mathrm{N} / \mathrm{A}$ & $\mathrm{N} / \mathrm{A}$ \\
\hline Tracer gas $^{b}$ & $\begin{array}{l}\text { Sash full open; } \\
\text { breathing zone } \\
\text { @ } 18 \text { inches }\end{array}$ & $40 \%$ & Pass & Pass & Pass & $\mathrm{N} / \mathrm{A}$ \\
\hline Tracer gas $^{b}$ & $\begin{array}{l}\text { Sash full open; } \\
\text { breathing zone } \\
\text { @ } 18 \text { inches }\end{array}$ & $33 \%$ & Fail & Fail & Fail & $\mathrm{N} / \mathrm{A}$ \\
\hline
\end{tabular}

a. Face velocity Pass/Fail criterion per CAL/OSHA 5154.1.

b. Tracer gas Pass/Fail criterion per ANSI Z9.5 1992.

c. Fail criterion per NIH (1996); marginal pass per ANSI Z9.5 1992.

$\mathrm{N} / \mathrm{A}=$ not applicable or not done

\subsection{Widespread Benefits}

When cutting airflow by up to 70 percent in standard laboratory fume hood installations, we estimate that California laboratories could save 360 to 720 Gigawatt-hours (GWh) of electricity annually, and 100 to 200 megawatts of electrical peak generating capacity. This energy savings equates to about $\$ 41$ to $\$ 82$ million per year, or $\$ 1,000 /$ year/hood, with higher savings likely in most other U.S. climates. Nationwide, total annual savings are estimated to be $\$ 240$ 480 million, ${ }^{1}$ corresponding to 2,100 to $4,200 \mathrm{GWh}$ annual electricity production and 600 to $1,200 \mathrm{GW}$ of peak electrical capacity.

Beyond ventilation reduction and associated energy savings, the Berkeley Hood offers design features that deliver a range of benefits:

1. Simpler design than state-of-the-art variable air volume (VAV) fume hood systems offers more certain energy savings, coupled with easier and less expensive installations and maintenance.

2. Constant volume operation ensures energy savings are independent of operator interface.

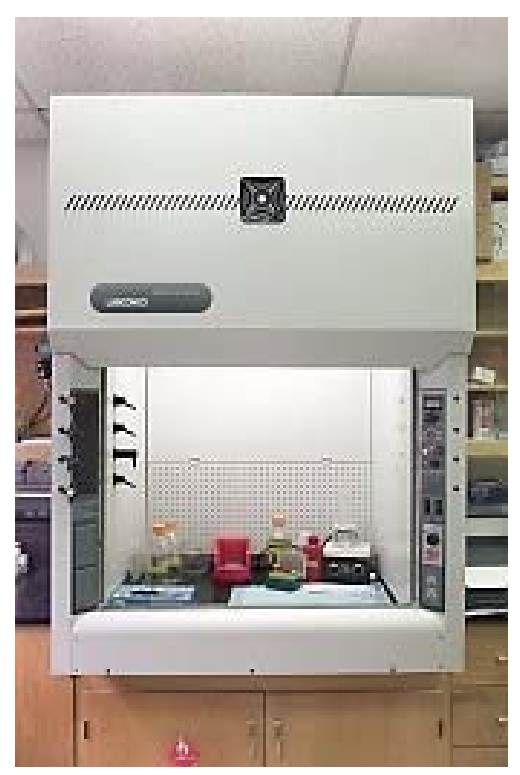

Figure ES-5. Labconco alpha prototype Berkeley Hood.

\footnotetext{
${ }^{1}$ These estimates predate the energy crisis of 2001, at which time prevailing energy prices were three to four times higher in some areas than those used in this analysis $(\$ 0.08 / \mathrm{kWh}$ for electricity and $\$ 120 / \mathrm{kW}$ demand charges).
} 
3. Improved containment reduces dangerous airflow patterns, eddy currents, and vortexes.

4. Clean room air flowing, into the operator's breathing zone reduces potential hazard from fumes.

In new construction projects, designers specifying the Berkeley Hood can achieve savings in energy, construction, and maintenance costs. While the Berkeley Hood itself is expected to have a direct first-cost premium over a current standard hood, this cost can be offset with first-cost savings from smaller ducts, fans, and central plants, as well as simpler control systems for VAV, offering lower overall first cost than standard or VAV hood systems.

In retrofit projects, Berkeley Hood users can receive critical HVAC system benefits beyond energy savings. Many laboratories are "starved" for air as their need for hoods has grown over the years. As a result, low supply or exhaust airflows cause inadequate exhaust, in some cases, potentially leading to contaminant spills from the hood. Since increasing supply airflow is very costly in most cases, many laboratories cannot add new hoods. By replacing existing hoods with Berkeley Hoods, users can increase the number of hoods or improve exhaust performance, or both. The final result is improved research productivity, enhanced safety, and lower energy bills.

\subsection{Project Supporters}

Although PG\&E provided funding for this field test, additional funding and other forms of support have been provided by the following organizations to address various closely related aspects of the hood's development and testing:

1. U.S. Department of Energy... Multi-year funding for hood development and to develop intellectual property.

2. California Institute for Energy Efficiency (CIEE)... 1998 to 1999 for technology development and technology transfer.

The following organizations provided in-kind support:

1. Labconco... Provided a fume hood superstructure for modification and use in prototype development. Built prototype for demonstration installation and field testing.

2. Fisher-Nickel/PG\&E Food Service Technology Center (FSTC)... Collaborated by sharing ideas and methods to visualize airflow in hoods. Used FSTC schlieren device to study Berkeley Hood airflow patterns. LBNL presented at conferences sponsored by FSTC to demonstrate airflow visualization techniques.

3. Siemens Building Technologies and Controls... Provided monitoring and control equipment and expertise for field test.

4. US Filter/Johnson Screens... Provided protective grill for lower plenum supply at reduced cost; worked with LBNL to design and fabricate special grill.

5. University of California at San Francisco... Provided site and funded installation for the first California demonstration of the Berkeley Hood.

6. The following organizations served as consultants to the project:

7. Exposure Control Technologies... Provided expert review and evaluation of Berkeley Hood at LBNL.

8. Knutson Ventilation... Provided expert review and evaluation of Berkeley Hood at LBNL.

9. Marina Medical Mechanical... Installed the Berkeley Hood at UCSF Medical Center in San Francisco.

10. SafeLab Corporation... Provided expert review and evaluation of Berkeley Hood at LBNL.

Other presentations (two videos, one brochure, and a detailed report on Berkeley hood) are available in the Appendix Section. 


\section{Task Three-High-Tech Buildings Market Transformation Support Activities}

The following market transformation activities were performed. Selected documents relevant to these market transformation activities are provided in the Appendices.

1. Participation in "Whole Building Energy Benchmarking Applications and Techniques" at the Pacific Energy Center on March 7, 2000. Mary Ann Piette (LBNL researcher) presented benchmarking techniques used in commercial buildings. Click here (or see Appendix T3-1) for the presentation file.

2. Participation in ASHRAE bi-annual meetings. Related presentation materials are provided.

a. Winter meeting in Dallas, TX on February 6-9, 2000, as a corresponding member of the ASHRAE TC 9-11 (cleanroom) committee. Click here (or see Appendix T3-2) for the presentation file.

b. Summer meeting in Minneapolis, MN on June 25-27, 2000, as a corresponding member of the ASHRAE cleanroom committee. Bill Tschudi and Stephen Fok presented a seminar at the conference covering energy efficiency opportunities in cleanrooms, and attended Technical Committee TC 9-11 meeting. Click here (Part A and Part B,-or see Appendix T3-3 and T3-4) for the presentation files.

c. Prepared and submitted an abstract for a seminar presentation at the ASHRAE winter 2001 meeting in Atlanta. Due to the volume of seminar applicants this was deferred to the summer 2001 meeting in Cincinnati. As a result, this meeting was not attended.

d. Summer meeting in Cincinnati, OH on June 23-27, 2001, as corresponding members of ASHRAE TC 9-10 and 9-11 committees. Bill Tschudi presented a seminar on cleanroom programming and benchmarking and attended the cleanroom committee meetings. Geoffrey Bell attended the laboratory committee meetings.

Click here (or see Appendix T3-5) for the presentation file.

3. Participation Cleanrooms East/West Conferences, which are attended by cleanroom owners, operators, and design and construction professionals.

a. Organization of, and participation in a panel discussion on energy efficiency in cleanrooms at the Cleanrooms East conference (hosted by Pennwell) on March 27-29, 2000, in Baltimore, MD.

b. Presented a seminar on cleanroom energy benchmarking at the Cleanrooms West conference on October 35, 2000 in Portland, OR. Click here (or see Appendix T3-6) for the presentation file.

c. Presented a seminar on a proposed standardized test procedure for fan-filter units. This seminar was jointly presented by Dr. Fanghei Tsau of the Industrial Technology Research Institute (ITRI), Hsinchu, Taiwan. The presentation was given on October 9, 2001 at the Cleanrooms West conference in San Jose, CA. Click here (or see Appendix T3-7) for the presentation file.

4. Participation in two ACEEE conferences. Relevant presentations and papers are provided in the following:

a. ACEEE 2000 Summer Study, August 2000-Presentation of a paper titled "Strategies for Energy Benchmarking in Cleanrooms and Laboratory-Type Facilities," proceedings of the ACEEE 2000 Summer Study on Energy Efficiency in Buildings. D. Sartor, M.A. Piette, W. Tschudi, and S. Fok, LBNL Report45928. Presented by Dale Sartor. Click here (or see Appendix T3-8) for the presentation file, and click here (or see Appendix T3-9) for the paper file.

b. ACEEE 2001 Summer Study on Energy Efficiency in Industry, July 2001. Present a paper titled "Cleanroom Energy Benchmarking in High-Tech and Biotech Industries," William Tschudi, Kathleen Benschine, Stephen Fok, and Peter Rumsey, LBNL Report- 47729 (or see Appendix T3-10). Click here (or see Appendix T3-11) for the presentation file.

5. Participation in industry activities pertaining to fume hood operation and safety. These include participation in ASHRAE's TC 9-10 (Laboratory) Technical Committee. Click here (or see Appendix T3-12) for the presentation file, for ASHRAE Guideline ANSI/ASHRAE 110-1995, Method of Testing Performance of Laboratory Fume Hoods, and CAL/OSHA's advisory committee to the Standards Board to review and recommend changes proposed to their standard 5154.1 Ventilation Requirements for Laboratory-Type Hood Operations. 
6. Coordination of the Laboratories for the 21st Century activities. Click here (or see Appendix T3-13) for the website homepage.

a. Coordination of conference held in San Francisco on September 5-8, 2000. The project team participated in presentations, panels, and a demonstration of the low flow fume hood at the Pacific Energy Center. The conference was a success in that there was broad attendance and high interest level in improving laboratory energy efficiency. LBNL presentations included a description of the cleanroom benchmarking project and the High-Performance Fume Hood technology.

b. Presentation of cleanroom benchmarking results at LABS 21 conference held in Washington, DC. Click here (or see Appendix T3-14) for the presentation file.

7. Participation in the PG\&E hosted workshops, Roundtable, and Expo:

a. Participation in an Expo in San Jose, on July 13, 2000, including a presentation to Silicon Valley businesses on cleanroom benchmarking activities. Click here (or see Appendix T3-15) for the presentation file.

b. Participation in a workshop for Silicon Valley manufacturers, including a presentation on energy efficiency ideas for cleanrooms and data centers on April 4, 2001. Click here (or see Appendix T3-16) for the agenda, and here (or see Appendix T3-17) for the presentation file.

c. Participation in PG\&E workshop on flow visualization using the Schlieren visualization tool and demonstration with a hydrogen bubble generator.

d. Participation in the industry focused roundtable meetings hosted by PG\&E on December 12, 2000. This included presentations on the cleanroom benchmarking results and the need for a roadmap for high-tech buildings R\&D. Following the presentations, the participants provided input to the roadmap. Considerable industry feedback on needed research and market transformation activities for these energy intensive buildings was obtained. The group then prioritized the ideas presented. Click here for the relevant files. Click here (or see Appendix T3-18) for benchmarking results; click here (file 1 and file 2-or see Appendices T3-19 and T3-20) for roundtable discussion; and here (or see Appendix T3-21) for roadmap input. The following is a list of the highest priority needs, as determined by the group:

\begin{tabular}{|c|c|}
\hline $\begin{array}{l}\text { - Design Intent Tool } \\
\text { - Design Guide } \\
\text { - Reduce distance between } \\
\text { process tools and vacuum pumps } \\
\text { - Integrate team members } \\
\text { (designer, operator, } \\
\text { maintenance, etc.) } \\
\text { - Get the loads right } \\
\text { - Heat recovery } \\
\text { - HVAC } \\
\text { - Controls }\end{array}$ & $\begin{array}{ll}\text { - } & \text { Use of mini-environments } \\
\text { - } & \text { efficiency } \\
\text { - } & \text { Benchmarking } \\
\text { - } & \text { Commissioning } \\
\text { - } & \text { Preventative maintenance } \\
\text { - } & \text { Peak load reduction strategies } \\
\text { - } & \text { IEST/ISO standards (scientific } \\
\text { - } & \text { basis for recommendations) } \\
& \text { (scientific basis for } \\
\text { - } & \text { Vacuuirements) } \\
\text { - }\end{array}$ \\
\hline
\end{tabular}

e. Participation in the industry roundtable meeting hosted by PG\&E on November 14, 2001. This included presentations of the final cleanroom benchmarking results. It also included a presentation of the Cleanroom Programming Guide being developed through other funding at LBNL. Following the presentations, the participants provided input to the guide. Click here for the benchmarking presentation. Click here for the programming guide presentation. 
8. Presentation of high-tech building's energy efficiency opportunities to the National Association of State Energy Officials (NASEO) for their annual meeting in September, 2000 at Redondo Beach, CA by Dale Sartor. Click here (or see Appendix T3-22) for the presentation file.

9. Collaboration with the Northwest Energy Efficiency Alliance's high tech market transformation activities was ongoing during the project. Presentations were made at NEEA workshops held in Portland, OR.

a. Bill Tschudi and Stephen Fok presented an update of the PG\&E sponsored high-tech building market transformation activities at a workshop on May 3, 2000. Approximately 30 key high-tech facility staff attended this meeting. Click here (or see Appendix T3-23) for the presentation file.

b. Bill Tschudi presented energy efficiency strategies for high tech buildings at a workshop in Portland, OR on May 22, 2001. Approximately 50 key high tech facility staff attended. Click here (or see Appendix T3-24) for the presentation file.

10. An abstract for a presentation concerning a test standard for fan-filter units at the Semicon conference in July 2001 was prepared and submitted. Although the conference did not select this abstract for a presentation, the topic was accepted for presentation at the Cleanrooms West conference in San Jose, CA in October 2001. Click here (or see Appendix T3-25) for the presentation file.

11. Publications in the popular and trade press.

A number of organizations have recognized the Berkeley Hood's importance and potential impact and have publicized it or otherwise recognized it. These include:

a. UniSci - Daily University Science News; 18 Jan 2000; news article.

b. Laboratory Network.com; News and Analysis web site, 25 Jan. 2000; article.

c. The Alchemist, trade organization's web site, 27 Jan. 2000; news article.

d. The Daily Californian, Sci-Tech section, 14 February 2000; newspaper and web article.

e. Daily University Science News, January 18, 2000

f. E-Source Tech News Vol. 1 Issue 1, 18 February 2000; article.

g. Advanced Manufacturing Technology Alert, 18 Feb. 2000; news article.

h. DOE This Month, March 2000; article.

i. ATMI's advertisement in Cleanrooms, Vol. 14, No. 3, a trade journal, March 2000.

j. Patent Announcement in Cleanrooms, Vol. 14, No. 10, October 2000.

k. San Francisco Chronicle, article on the front page of the Business Section, Sunday, 28 January 2001.

1. Consulting Specifying Engineer, article forthcoming

\section{Recommendations for Future Activities}

Recommendations for future high-tech facilities energy efficiency activities include:

\section{Cleanroom Benchmarking Activities}

1. Perform a study to follow-up with each of the project participants to determine which recommendations from the PG\&E benchmarking project were implemented, and identify reasons for any recommendations not being adopted. A summary of success stories for the measures that were adopted would be assembled, published, and presented to other PG\&E customers who did not participate in the benchmarking. Barriers to implementation would be identified and factored into future planning for this market.

2. Populate the cleanroom energy benchmark database with additional cleanrooms of various cleanliness classifications (energy intensity). This data could be obtained through various means such as through additional site measurement or purchase of existing data. This should be a continuous effort because currently only very limited measured data exists. It would be useful to include cleanrooms of other industries to further determine common issues affecting energy performance. The database would be useful to track performance improvement trends over time. 
3. Develop a design based cleanroom energy benchmarking tool. This protocol would allow prediction of actual energy use for various designs and would be useful for building owners to benchmark system performance without measurement. It would be useful to provide guidance for cleanroom designers and owners during the design of new or modified cleanrooms, and it would provide a rough approximation of the performance of existing systems in absence of actual measured data.

4. Develop a training course for cleanroom facility managers to encourage benchmarking, identify efficiency opportunities, identify best practices, and disseminate other related efficiency program data. Existing efficiency resources for major commercial and industrial focus areas should be better publicized for this market. Programs such as PG\&E's Cool Tools (http://www.hvacexchange.com/cooltools/index.html) project, DOE's Motor Challenge and Compressed Air Challenge (http://www.knowpressure.org/html/sourcebook/index.htm), and others have direct applicability to the cleanroom market but appear to be not well understood by those servicing this market. Targeted training sessions or a guide focused on these types of programs for the cleanroom market should result in significant improvements. Minimum efficiency targets could be established for new or retrofit design based upon benchmark results. As the data set expands, building owners will be able to select a desired operating point and set minimum efficiency targets as a design parameter. Industries, fearing regulation, will resist any initiatives for others to set universal targets for them so this should only be suggested through design assistance programs.

5. Develop best practices based upon an expanded set of cleanroom energy benchmarking results. Prepare case studies of best performing systems to document findings. Publish results on the LBNL cleanrooms website and present these at industry conferences.

\section{Cleanroom Efficiency Improvement Activities}

1. Recommended air change rates in cleanroom recirculation air systems need refinement. Currently ranges of airflow are recommended by IEST based upon outdated rules of thumb. A scientifically based range of airflow needs to be developed for each cleanliness class taking into consideration such issues as room turbulence, defect particle size and composition, distribution schemes, etc. While developing such a scientifically justified basis is a significant undertaking, cleanroom operators can still achieve good results through small incremental changes while carefully observing production impact. This task would likely involve a combination of Computational Fluid Dynamics computer simulation and testing for particulates for various configurations and airflows.

2. Develop a standardized test procedure for fan-filter units commonly used in cleanrooms to provide a standardized comparison of energy performance. Currently designers and owners have no direct comparison information for energy performance of these devices. Work with an industry partner(s) to promote use of the standard test procedure and work to get it adopted as a standard by AMCA.

3. Develop a cleanroom design case study based upon the use of a new cleanroom programming guide being developed by LBNL with California public goods research funding. This would provide an integrated research and market transformation approach to introduce a product with immediate benefit to high-tech industries. Lessons learned through the benchmarking project would contribute to this work.

4. Develop the cleanroom programming guide into a web-based tool with enhanced links to other useful design information.

5. Develop and demonstrate the ability to place semiconductor process equipment (tools) into a reduced energy, idle mode (sleep mode). By working with an industry partner, analyze tool performance and recommend modifications to allow a reduced energy use while the tool is idle. Publicize the ability to place a tool in "sleep mode" to encourage use of this concept in other process tools.

6. Air management systems' efficiencies vary significantly. Owners consider many factors to determine which air management system is the right choice for their application, and energy in the past has not been a major factor. The challenge is to get owners and designers to consider initial cost, and operating cost through life-cycle budgeting. Application of a tool such as the LBNL Cleanroom Programming Guide in combination with other guidance on life-cycle cost analysis is recommended. Case studies using a guide to programming should be performed and energy improvement documented and presented back to industry. 
7. Strategies for better determining process heat load removal, incremental build-out scenarios, control systems, and flexibility for growth should be pursued. Correctly sizing HVAC systems and process cooling systems for efficient full and part load operation should be a priority. Better techniques and strategies are needed to more accurately estimate process load and how it varies over the life of the facility. Part load operation and reliability issues need to be considered. These items could be developed into a design guideline to the industry owners who operate cleanrooms.

8. Develop a methodology to assess cleanroom envelope air leakage and perform several case studies to baseline typical cleanroom leakage rates and identify improvement opportunities.

9. Continue outreach through ASHRAE, ACEEE, Sematech, Silicon Valley Manufacturing Group, Northwest Energy Efficiency Alliance, SEMICON, Cleanrooms West, etc. Update and expand LBNL's cleanroom web site. Develop and present selected topics at the Pacific Energy Center.

10. Assist in the design and implementation of a pilot rebate program targeted at the unique needs of high tech industrial customers.

\section{Berkeley Hood Public-Interest R\&D and Market Assessment}

Although the Berkeley Hood is well on its way to commercialization, numerous hurdles remain to be overcome before facility owners or designers can easily integrate this technology into their projects and before manufacturers will invest in bringing the technology to market. This section summarizes a number of public-interest activities required to bridge the gap between the present status of the Berkeley Hood and its ultimate success in the marketplace. We divide the presentation into Technology Development and Market Development activities.

Ongoing activity is funded in the near term by several sources (e.g. DOE, CEC, PG\&E, and SDSU/SDG\&E), much of which is specifically targeted for field tests and demonstrations. Most of the technology development and some of the market development involves multi-year activities are only partially funded at present.

\section{Fume Hood Technology Development}

1. Safety testing and monitoring techniques. This is a key area, and the project is currently developing an inhouse capability for doing so, and is also participating with various professional committees to improve prevailing testing standards. Subsequent work needed includes development of less costly test methods, more systematically defining the safe operational envelope for the Berkeley Hood, development of feedback-control systems that work in conjunction with real-time monitoring. In addition to standard tests, it is important to gain a better understanding of real-world conditions that are not evaluated by standard tests, such as the movement of people near the hood entry.

2. Creation of next-generation prototypes. Wider hood openings are more typical in practice than the four-foot format of the first-generation Berkeley Hood, and will likely present new challenges not addressed in the current hood. One area remaining to be resolved are supply-air geometries to ensure that interior surfaces are "swept" and improved interior designs (baffles, foils, plenums, fan systems) to better improve fume removal. Also important is the integration of sensor-based controls to optimize energy performance and ensure safety. The significant potential for "air-divider" retrofits to existing, standard hoods should also be evaluated. Preliminary design work focusing on hood lighting has been very successful; the results should be tested in a real-world prototype mockup with user evaluation.

3. Failure modes. Much is yet to be understood about failure modes. Valuable work would include identifying points of tracer gas concentration, understanding the implication of general laboratory exhaust in failures and possible control/response modes, and designing to preclude the potential adverse dynamics created by multiple Berkeley Hoods simultaneously operating in the same room. The interactions of standard hoods and Berkeley Hoods located in the same laboratory space should also be evaluated.

4. Computational Fluid Dynamics (CFD) modeling. Initial progress with CFD modeling suggests that this is a powerful tool with considerable untapped potential. One need is to expand from two-dimensional to threedimensional models. Additional CFD modeling activity could, for example, integrate a simulated $\mathrm{SF}_{6}$ ejector or the impacts of operators on turbulence, and could evaluate the hood's safety performance at varying breathingzone heights. CFD models could be used extensively to further optimize an array of hood features ranging from geometry to air distribution approaches. More subtle influences on hood performance, such as temperature, and factors leading to contaminant spills. 
5. Systems interactions. Beyond the hood itself, work is needed on the interactions of hoods with the general laboratory and HVAC system. Better understanding is needed of the effects of pressurization fluctuations and other phenomena associated with supply air diffusers, doorways, general exhaust systems, doorways, etc. The failure of the pre-existing UCSF hood (due to open windows and missing ceiling tiles) highlights the relevance of system-level interactions.

\section{Fume Hood Market Development}

1. Energy savings potential. Although a very significant energy savings potential appears to exist, our initial energy impact analysis is highly generalized and hinges on a number of key assumptions. Improved data are needed on the overall population of hoods, current sales rates, geographical distribution, and baseline energy use of standard hoods across a range of climatic settings. For example, our current savings analysis is based on four-foot hoods, while in practice many hoods are wider (with correspondingly larger airflows and energy use). The current analysis has not delved into space-heating savings, which would be significant in some regions.

2. Industry partnerships. Continued industry partnerships are also a critical-path issue. Current activities include working with the fume hood industry leaders to fabricate of a wider (6-foot) prototype and development improved monitoring and control systems. Licensing the existing technology to industrial partners is clearly a key need.

3. Other hood market segments. While the effort thus far has focused on standard laboratory-bench environments, alternate designs should be developed that serve other applications (e.g. wet benches). Doing so could considerably expand the energy savings potential.

4. Outreach. Outreach activities should include continued maintenance and development of the Berkeley Hood website, presentations, and publications in professional and popular literature.

5. Liaison with professional societies. Augmenting the above market-focused activities, continued involvement in professional societies is necessary to overcome significant barriers to commercialization posed by testing standards that unwittingly discriminate against the Berkeley Hood.

6. Business case. Improved energy analysis, coupled with cost-benefit information, should be assembled into a coherent business case. Also required is a more rigorous assembly of test data, with special emphasis on energy and safety performance comparisons with standard hoods. This should incorporate laboratory test data as well as field tests and user feedback in working laboratories.

\section{Other Activities}

Demonstrate use of the Laboratory Design Intent Tool being developed by LBNL on a high-tech facility. This tool is also being developed with California public goods research funding and would similarly provide for integrating research and market transformation to introduce this tool.

Incorporate data centers into the high-tech buildings program. Perform market research and benchmark energy use for several sizes and configurations of data centers. Prepare case studies and identify energy-efficiency improvement opportunities.

\section{Acknowledgement}

We wish to thank Stephen Fok (Project Manager), Kathleen Benshine, Carol Harty, Pat Eilert, Ken Gillespie, Charlie Middleton, Jane Ng (all from PG\&E), Keith Rothenberg (PG\&E consultant), Karl Brown, Ed Vine (both from CIEE) for their support and valuable input throughout the course of this project. We also wish to thank Larry Chu, Leslie Hummel, Kim Kraber, Joe Regester, Peter Rumsey, Peter Stevens, John Weale (all from Rumsey Engineers, formerly Supersymmetry) for obtaining site data for the project and preparing site reports; LBL staff for their contribution Don Aumann, and Mary Ann Piette; Zhongning Chen (LBNL summer intern) for his assistance and contribution to the cleanroom energy benchmarking database. Finally, we also wish to thank a number of anonymous industrial participants for participating in the benchmarking, and their cooperation during the course of this project. This project is funded by California utility customers and is administered by Pacific Gas and Electric Company under the auspices of the California Public Utilities Commission. Copyright @ 2001 Pacific Gas and 
Electric Company. All rights reserved. The research reported here was funded, in part, by the California institute for Energy Efficiency (CIEE), a research unit of the University of California. Publication of research results does not imply CIEE endorsement of or agreement with these findings, nor that of any CIEE sponsor. This work was also supported by the Assistant Secretary for Energy Efficiency and Renewable Energy, Office of Building Technology, State and Community Programs, Office of Building Research and Standards of the U.S. Department of Energy under Contract No. DE-AC03-76SF00098. 


\section{Appendix}

\section{Task One-Cleanroom Energy Benchmarking}

General Cleanroom Benchmarking Plan

A General Cleanroom Benchmarking Plan was developed to guide the scope of the work in cleanroom benchmarking. The general plan can be viewed by clicking here (or see Appendix T1-1).

Site Reports

The main body of each site report summary is in the appendix. These include 14 cleanrooms at 7 facilities. Comprehensive data and figures are not included but were previously furnished to PG\&E for each of the facilities.
A...Click $\underline{\text { Site } 1}$ (or see Appendix T1-2) - Facility A ( 2 cleanrooms) CR 3,10
B. .. Click Site 2 (or see Appendix T1-3) - Facility B.1 (2 cleanrooms) CR 11,12
C. .. Click $\underline{\text { Site } 3}$ (or see Appendix T1-4) - Facility B.2 (2 cleanrooms) CR 13,14
D. .. Click Site 4 (or see Appendix T1-5) - Facility C (1 cleanrooms) CR 15
E. .. Click $\underline{\text { Site } 5}$ (or see Appendix T1-6) - Facility D (1 cleanrooms) CR 16
F....Click Site 6 (or see Appendix T1-7) - Facility E (2 cleanrooms) CR 17,18
G. .. Click Site 7 (or see Appendix T1-8) - Facility F (4 cleanrooms) CR 19-22

\section{Task Two-High-Performance Fume Hood Demonstration and Test}

Berkeley Hood Demonstration, UCSF. Click here (or see Appendix T2-1) for the presentation file.

Click here (Video 1, Video 2) to see videos of the fume hood operating using theatrical smoke for visualization, as well as a description of the technology.

A brochure was prepared to publicize the technology. Click here (or see Appendix T2-4) to see the HighPerformance Berkeley Hood Brochure.

Click here (or see Appendix T2-5) for the detailed report (LBID-2396) on the Berkeley hood test and for considerable background information on other fume hood work underway at LBNL.

\section{Task Three-High-Tech Buildings Market Transformation Support Activities}

Appendices T3-1 through T3-25. 